\title{
Formas de aprendizagem e graus de inovação de produto no Brasil: uma análise exploratória dos padrões setoriais de aprendizagem
}

Forms of learning and product innovation degrees in Brazil: an exploratory analysis of sectoral learning standards

\begin{abstract}
This paper aims to broaden the understanding of innovation dynamics in Brazilian firms. For doing so, we constructed indicators of 'types of learning' and 'degrees of innovation' and their relationships were econometrically tested. Significant sectoral differences were found. It was also found that: (i) 'higher degree' innovations arise from forms of learning that combine both codified knowledge (such as knowledge arising from advanced S\&T sources) and tacit knowledge (resulting from customer interactions, for example); (ii) 'lesser degree' innovations derive almost exclusively from forms of learning that consider only tacit knowledge; and (iii) customers are always important sources for innovation processes. From the latter finding, we hypothesized that the limited dynamic innovation found in Brazilian firms can be explained by a type of 'lock-in effect' related to customers' demands for quality. The stimulus to exports is the main policy recommendation derived from this analysis, by admitting that more sophisticated customers may induce the most promising technological trajectories.
\end{abstract}

\section{Keywords}

product innovation; forms of learning; learning by exporting.

JEL Code O33.

\author{
Pablo Felipe Bittencourt \\ Universidade Federal de Santa Catarina \\ Jorge Nogueira de Paiva Britto \\ Universidade Federal Fluminense \\ Ricardo Giglio \\ Christian-Albrechts-Universitaet
}

\section{Resumo}

O objetivo do artigo é ampliar a compreensão da dinâmica da inovação das firmas brasileiras. Para isso, indicadores de tipos de aprendizagem e graus de inovação foram construídos, e suas relações testadas econometricamente. Dentre os resultados, além de diferenças setoriais significativas, destacamos: (i) que inovações de maior grau decorrem de formas de aprendizagem que combinam conhecimentos codificados (como os advindos das fontes avançadas de C\&T) com tácitos (frutos de interação com clientes, por exemplo); (ii) que as inovações de menor grau derivam, quase que exclusivamente, da aprendizagem de conhecimentos tácitos e, que, (iii) os clientes são sempre fontes importantes aos processos de inovação. Desta última constatação, levantamos a hipótese de que a limitada dinâmica inovadora das firmas brasileiras pode ser explicada por um aprisionamento à qualidade das demandas de seus clientes. O estímulo às exportações é a principal recomendação de politica derivada, por admitir-se que clientes mais sofisticados poderão induzir trajetórias tecnológicas mais promissoras.

\section{Palavras-chave}

inovação em produto; formas de aprendizagem; aprendizado pela exportação.

Códigos JEL O33. 


\section{Introdução}

A inovação é um processo interativo que combina conhecimentos de fontes distintas localizadas no interior da firma, mas também fora dela (Lundvall, 1988). Tal afirmação, amplamente explorada e aceita pela literatura recente da economia da inovação, pode ser qualificada em função do grau específico da inovação a que se refere. A literatura empírica recente não é consensual sobre a(s) forma(s) de aprendizagem que explicaria(m) os diferentes graus de inovação. Há, no entanto, fortes indícios, por exemplo, da combinação do uso da P\&D interna com as fontes avançadas de C\&T (universidades e centros tecnológicos e de pesquisa) nos processos de geração de inovações de grau superior, ao passo que as inovações de menor grau seriam derivadas primordialmente da aprendizagem com fontes da esfera produtiva como clientes, fornecedores e concorrentes. Em geral, tal afirmação se baseia em aplicações de técnicas estatísticas em dados de países desenvolvidos ou dotados de um Sistema Nacional de Inovações (SNI) mais sofisticado.

O desenvolvimento histórico do Sistema Nacional de Inovações brasileiro resultou no enraizamento de determinadas características, como o pouco uso das fontes avançadas de C\&T, que dificultam o estabelecimento de analogias diretas com as evidências empíricas observadas em países desenvolvidos. Entretanto, ainda que a posição periférica do SNI brasileiro implique condicionantes negativos à difusão de tecnologias com maior grau de sofisticação (Bell; Pavitt, 1995; Lemos et al., 2005), uma característica bastante evidente do SNI brasileiro é a ampla diversidade de nível de competência dos agentes, tanto no plano intersetorial como no plano intrassetorial. Exemplos de excelência, como o domínio tecnológico da Petrobras na exploração de petróleo em águas profundas, ou da WEG no desenvolvimento de motores elétricos, convivem com atrasos em diversas indústrias como as de móveis e madeira e de têxteis e confecções ainda muito baseadas em vantagens comparativas de custos de recursos naturais e de trabalho e, que, talvez por isso, ainda não tenham despertado para a aplicação de bio e nano tecnologias em seus produtos, como tem ocorrido em países desenvolvidos.

Este artigo contribui a essa linha de pesquisa ao apresentar evidências empíricas que subsidiam as análises típicas dos processos de inovação no Sistema Nacional de Inovações brasileiro, considerando diferenças seto- 
riais. Especificamente, procura-se avaliar a associação entre as formas de aprendizagem e os graus de inovação de produto, para a empresa e o mercado nacional, por meio de análises que contemplam o conjunto de setores da indústria brasileira e em quatro conjuntos de setores, seguindo a sugestão de Bittencourt (2012).

Com base em uma discussão teórica preliminar, emerge a hipótese de que inovações para o mercado nacional (de maior grau) estão associadas ao uso de um conjunto maior de formas de aprendizagem, comparativamente às inovações para a empresa (de menor grau). A segunda hipótese é associada aos padrões setoriais de aprendizagem e, mais especificamente, às diferenças que os definem. A hipótese é que as intensidades díspares das formas de aprendizagem, que definem os conjuntos de setores similares (padrões), explicam diferentes formas setoriais de aprender para inovar em produto.

O trabalho está dividido em quatro seções, além desta introdução. A segunda apresenta o referencial teórico, que orienta a análise empírica, abordando dois aspectos detalhados em subseções específicas: na primeira, são discutidas evidências teóricas e empíricas da associação entre formas de aprendizagem e graus de inovação; na segunda, a discussão refere-se a possíveis impactos das formas de aprendizado sobre as inovações de produto. Na terceira seção, são exibidos os padrões setoriais de aprendizagem e a metodologia estatística. A quarta seção é de apresentação e discussão dos resultados da pesquisa. A última é conclusiva.

\section{Referencial teórico}

\subsection{Formas, aprendizagem e graus de inovação: evidências teóricas e empíricas}

A velocidade das transformações recentes e a intensidade da concorrência possibilitam a geração de vantagem competitiva para empresas ágeis e abertas em termos de adaptação e inovação. $O$ processo de aprendizado que emerge dessa necessidade envolve fontes de informação internas e externas à firma. De maneira geral, o aprendizado interno articula-se às funções principais da empresa ( $\mathrm{P} \& \mathrm{D}$, produção, marketing, e organização). Esse aprendizado pode decorrer das práticas corriqueiras internas à empre- 
sa, como o esforço de produzir (learning-by-doing) e do uso de máquinas e equipamentos (learning-by-using). Pode também ser resultante de esforços sistematizados de busca, relacionados ao aprimoramento e à criação de novos produtos e processos produtivos (learning-by-searching). Todavia, em função do custo crescente no desenvolvimento de novas tecnologias, da multidisciplinaridade de novos conhecimentos e da natureza sistêmica e complexa de novos produtos e processos, sugere-se que o aprendizado interno deva articular-se a outro, externo à firma. Fora da firma, destaca-se a importância dos processos de aprendizado por interação (learning-by-interacting) com diversos agentes econômicos e não econômicos. A troca de informações com o ambiente externo, além de promover a atualização tecnológica, permite que, muitas vezes, conhecimentos acumulados tornem-se úteis e que o tempo para sua introdução seja reduzido, gerando uma vantagem competitiva significativa, que possibilita a ampliação das fatias de mercado e da lucratividade.

A aprendizagem externa não está relacionada apenas a estratégias de desenvolvimento de inovações de alto grau. É notada também em estratégias cujo foco é simplesmente a atualização em relação aos concorrentes, o que se reflete tipicamente em pequenas transformações nos produtos ou nos processos produtivos (Jaworski; Kohli, 1993). Nas análises empíricas sobre a relação das formas de aprendizagem e geração de inovações, frequentemente as inovações são subdivididas segundo seus graus, (a) para a empresa, e (b) para o mercado, ${ }^{1}$ admitindo-se que as primeiras possuem menor impacto do que as segundas. Tal subdivisão adapta-se às informações das bases de dados disponíveis, normalmente nas Pesquisas Nacionais de Inovações (National Innovation Surveys). Em grande medida, um papel destacado das universidades e dos departamentos internos de P\&D das empresas pode ser notado, especificamente, no que se refere à geração de inovação de maior grau. Os resultados de Caloghirou et al. (2004), a respeito das indústrias grega, italiana, dinamarquesa, inglesa, francesa, alemã e holandesa, de Tödtling et al. (2009), para a indústria austríaca, de Vega-Ju-

1 Para Viotti (2002), as inovações para a empresa no Brasil aproximar-se-iam mais do conceito de difusão tecnológica, se analisadas sob uma perspectiva analítica schumpeteriana rigorosa, ao passo que as inovações para o mercado referem-se a um tipo de mudança tecnológica mais próxima do conceito rigoroso de inovação, dado seu impacto na acumulação de conhecimentos e ganho de competitividade. Ainda que seja correto supor, com rigor, que as inovações "para a empresa" apresentem menor impacto do que as "para o mercado nacional", seria um equívoco aceitar uma analogia direta com inovações incrementais e radicais, respectivamente. 
rado et al., (2008), para a indústria espanhola, são exemplos. Enquanto que o uso de outras fontes como clientes, fornecedores e concorrentes aparece como combinado com um menor nível de $\mathrm{P} \& \mathrm{D}$, resultando na geração de inovações de menor grau (inovações para a empresa).

Já Jensen et al. (2007), em análise sobre a indústria dinamarquesa, distinguem duas formas de aprendizagem, uma cujos conhecimentos tácitos são mais intensivos (DOI mode, que inclui conhecimentos adquiridos mediante a aprendizagem by doing, using e interacting) ${ }^{2}$ e outra cujos conhecimentos codificados são mais intensos (STI mode, que inclui atividades de P\&D e a interação com universidades e centros de pesquisa). Os resultados são bastante instigantes e podem ser resumidos em três aspectos: (i) a probabilidade de ocorrência de inovações de produto aumenta quando as firmas se organizam (intencionalmente ou não) de forma a promover aprendizados DOI; (ii) firmas que promovem uma base científica forte (STI mode of learning) são mais inovativas e (iii), como aspecto mais importante, a capacidade inovadora é significativamente ampliada quando os dois modos de aprendizagem são combinados. Para os autores, a diversidade de fontes de aprendizagem associada ao maior potencial inovativo constitui evidência de que, na economia moderna, o conhecimento é o elemento mais importante, e o aprendizado, o processo mais fundamental para o incremento desse potencial (Lundvall, 2007).

Os resultados de outros estudos sobre o papel dos conhecimentos adquiridos de fontes externas (aprendizagem externa) são complementares e motivam este artigo. Laursen (2011), por exemplo, sobre a indústria dinamarquesa, com foco sobre o papel dos conhecimentos adquiridos dos clientes, observou que os nacionais foram muito relevantes para inovações de quaisquer graus, ao passo que os clientes internacionais revelaram importância destacada apenas para inovações de maior grau. Também Li e Vanhaverbeke (2009), em análise sobre a indústria canadense, apontaram a grande relevância do uso de fornecedores para a geração de inovações "pioneiras" (para o mercado mundial). Adicionalmente, Murovec e Prodan (2009), em análise das indústrias tcheca e espanhola, apontam a alta relevância de fontes de conhecimento industriais (fornecedores, clientes, concorrentes e de feiras e exposições), tanto para a geração de inovações de produto como de processo.

2 Inclui a interação com fornecedores, clientes e concorrentes. 
Considerando os possíveis controles usualmente realizados em análises desse tipo (porte das empresas, localização geográfica, setor de atuação, dentre outros), o recorte setorial apresenta-se como especialmente relevante. A ênfase nesse recorte remonta à análise de Nelson (1991), na qual é destacado que a diversidade de conhecimentos entre empresas articula-se à dimensão intersetorial, estando cristalizada na intensidade das atividades de $\mathrm{P} \& \mathrm{D}$, em outras atividades inovativas, na própria intensidade das inovações e também na estrutura de mercado subjacente. Além dele, Dosi (1988) e Breschi et al. (2000) destacam as características dos "regimes tecnológicos"3 como elementos capazes de definir tal diferenciação. A análise empírica de Veja-Jurado et al. (2008), por exemplo, cuja referência de corte setorial foi a seminal taxonomia de Pavitt (1984), ${ }^{4}$ encontrou significância da aprendizagem tanto de fontes de conhecimento industriais (clientes, fornecedores e concorrentes) como das não industriais (universidades), tanto para inovações "para a empresa" como "para o mercado", quando analisadas empresas inseridas nos setores "dominados por fornecedores" e "intensivos em escala". Dentre os setores "fornecedores especializados", as fontes industriais foram mais significativas no caso do desenvolvimento de inovações para a empresa, enquanto que as universidades e os centros de pesquisa foram mais relevantes no caso do desenvolvimento de inovações para o mercado nacional. Finalmente, para os setores "baseados em ciência", apenas as fontes científicas foram significantes para quaisquer graus de inovação.

\subsection{Formas de aprendizagem e inovações de produto}

A importância do estoque de conhecimento como fator de aceleração de processos inovativos refere-se a inovações de produto, bem como a inovações de processo. A inovação no produto é mais visível e atrai maior atenção da literatura sobre inovação, estando associada a mudanças nas propriedades físico-químicas de determinado produto, que lhe permitem

3 Breschi et al. (2000) definem os regimes tecnológicos como combinações de oportunidades tecnológicas, apropriabilidade das inovações, cumulatividade dos avanços técnicos e propriedades da base de conhecimento.

4 A proposta de taxonomia da mudança tecnológica setorial de Pavitt (1984) diferencia setores como "dominados por fornecedores", "intensivos em produção", "baseados em ciência", sendo os dois últimos subdivididos como "fornecedores especializados" e "intensivos em escala". 
desempenhar uma determinada função de forma mais eficaz ou passar a desempenhar outras funções distintas daquelas que desempenhava originariamente. Quanto a esse aspecto, cabe ressaltar que muitas inovações apresentam caráter eminentemente "sistêmico", envolvendo a integração de conhecimentos provenientes de diferentes campos científicos e/ou áreas tecnológicas, conforme ressaltado em Imai e Baba (1991). Na medida em que as "inovações sistêmicas" requerem a integração de conhecimentos distintos e heterogêneos, as firmas geralmente se defrontam com desequilíbrios e estrangulamentos tecnológicos. Quando o número de campos técnico-científicos relevantes se eleva e novos requisitos em termos de competências críticas aparecem, as firmas podem se defrontar com um problema de "estrangulamento de capacitações" (capability squeeze) (Imai; Baba, 1991), reforçando a importância do acesso a fontes externas de conhecimento. A consolidação de articulações externas permite melhor "formatação" dos conhecimentos às exigências do processo inovativo, gerando efeitos do tipo spill over que incrementam o potencial inovativo dos agentes (Cohen; Levinthal, 1990).

O artigo investiga relações estatísticas entre a geração de inovações de produto e a variedade das fontes de aprendizagem internas e externas às empresas. Dentre as internas, destacam-se conhecimentos gerados a partir de Departamentos de $\mathrm{P} \& \mathrm{D}$, de engenharia e mesmo do chão de fábrica; já entre as externas, destacam-se conhecimentos associados às relações com fornecedores, clientes, competidores, universidades e outras fontes externas de pesquisa. Esta seção qualifica essas relações as quais serão investigadas empiricamente na seção quatro.

O conhecimento relevante que envolve a interação com fornecedores está normalmente associado à forma como componentes e insumos produtivos são utilizados pelas empresas inovadoras. Essa interação pode ajudar na percepção de problemas potenciais e acelerar o desenvolvimento de produtos como resposta a demandas de mercado (Li; Vanhaverbeke, 2009). Von Hippel (1988) destaca o fluxo de know-how tecnológico proveniente dos fornecedores no caso dos insumos mais importantes como fator de dinamização das inovações de produto, especialmente em setores "baseados em ciência". A análise de Nieto e Santamaria (2007) também destaca o papel de fornecedores-chave para a geração de inovação de produto.

A interação com clientes não apenas amplia as possibilidades de identificação de oportunidades de desenvolvimento tecnológico em produtos, 
como reduz a probabilidade de desenvolvimento de designs inapropriados nos primeiros estágios do processo de inovação, ou seja, quando o " $\mathrm{D}$ " do binômio "P\&D" ainda está em processo. Além disso, amplia as possibilidades de desenvolvimento de novas soluções à medida que as características que influenciam os demandantes são mais bem compreendidas (Lundvall, 1988; Von Hippel et al., 1999). Sendo assim, compreende-se que importantes conhecimentos tácitos (de difícil transmissão) podem estar envolvidos na avaliação da performance e das condições de funcionamento de um componente mecânico ou de uma máquina ou de um aparelho elétrico, ou mesmo da operacionalidade de um determinado software, os quais podem se mostrar essenciais para a modificação do produto e a aceleração de sua difusão entre outros usuários. ${ }^{5}$ Não obstante, envolver-se em redes com clientes com restritas exigências pode levar à evolução em trajetórias tecnológicas pouco promissoras Laursen (2011), o que compromete a mudança tecnológica virtuosa de longo prazo.

Firmas envolvidas na interação com competidores podem se beneficiar da troca de conhecimentos para solucionar problemas comuns. Ademais, empresas que interagem com seus competidores, ao obterem informações mais detalhadas a respeito de seus níveis tecnológicos, possuem melhores condições de se diferenciar. Contudo, compreender o conhecimento especializado desenvolvido pelos concorrentes pode não ser tarefa simples, uma vez que envolve intensamente conhecimentos tácitos e o desvendamento de segredos industriais. Nesse sentido, a capacidade de absorção pode ser decisiva como instrumento para identificação e compreensão das semelhanças e diferenças que distinguem a empresa da de seus competidores (Tsai; Wang, 2009).

Outro aspecto importante referente às fontes de aprendizagem externas às empresas é a articulação com a infraestrutura de C\&T. Nesse sentido, ainda que a literatura recente reconheça o papel diferenciado entre países no tocante à possibilidade de acesso a fontes avançadas de C\&T (Freeman, 1988; Suzigan et al., 2011) - não apenas os estímulos do território, como também a diversidade da base industrial, as competências técnicas acumuladas, os incentivos fiscais à pesquisa e à consolidação de

5 Assumir que esses conhecimentos podem estar dispersos em diversos trabalhadores das firmas usuárias das inovações, seja naqueles do chão de fábrica, seja em gerentes de produção, seja no pessoal de design e P\&D, torna mais factível a noção de tacitividade do conhecimento potencialmente envolvido na interação. 
mecanismos de transferência tecnológica -, pode-se dizer que, de modo geral, as interações com as fontes avançadas de C\&T constituem fonte poderosa de criação e disseminação de conhecimentos relevantes, possibilitando até mesmo melhor compreensão da empresa sobre o objeto da interação (Ahuja; Katila, 2001). Além do acesso às informações científicas e tecnológicas relevantes, a prestação de serviços técnicos especializados e o desenvolvimento de protótipos de novos produtos, propriamente ditos, constituem outros aspectos particularmente importantes da interação com as universidades e as instituições de pesquisa.

A possibilidade de acessar conhecimentos e aprofundar formas de aprendizado com fontes externas requer também a intensificação dos esforços inovativos realizados no interior das firmas, dadas as complementaridades existentes entre as duas instâncias. As atividades de P\&D, conduzidas por unidades especializadas nas firmas, estão normalmente engajadas na resolução de problemas científicos e/ou tecnológicos de considerável complexidade. Essas práticas podem possuir um caráter mais experimental-teórico ou mais orientado-aplicado, em função dos conhecimentos já acumulados na firma (Cohen; Levinthal, 1990), da orientação geral de sua estratégia tecnológica e de tendências definidas a partir do "regime tecnológico" subjacente (Breschi et al., 2000). Possuem, portanto, impacto relevante no fortalecimento do potencial das inovações de produto. Adicionalmente, o nível dos esforços em P\&D interno das firmas é, constantemente, relacionado à ampliação da capacidade de absorção tecnológica externa (Cohen; Levinthal, 1989).

Os esforços tecnológicos realizados no interior da firma, e seus possíveis impactos em termos do fortalecimento do potencial de geração de inovações de produto, não se resumem apenas às atividades de $\mathrm{P} \& \mathrm{D}$. $\mathrm{O}$ "aprender fazendo", ao referir-se às rotinas de produção da firma, excluindo-se as de $\mathrm{P} \& \mathrm{D}$, configura-se como elemento capaz de dinamizar as inovações de produto à medida que procedimentos técnicos típicos dessas estruturas sejam úteis. Ensaios, testes, o desenvolvimento de especificações técnicas e o melhoramento de características operacionais dos produtos (não incluídos nas rotinas de $\mathrm{P} \& \mathrm{D}$ ) estão entre as formas de aprendizagem inseridas aqui. Além disso, apesar de os mecanismos usuais de learning-by-doing estarem mais relacionados às inovações de processo, a diferenciação entre inovações de produto e processo pode ser relativamente tênue, na medida em que os dois tipos de inovação estão muitas vezes fortemente articulados, 
com a introdução de uma determinada inovação do produto, podendo requerer o desenvolvimento de novas tecnologias de produção bastante complexas, orientadas para o aumento da eficiência e da flexibilidade dos processos produtivos. Ainda no âmbito dos esforços inovativos e da difusão de conhecimentos intrafirma, destacam-se práticas de treinamento que, associadas aos conhecimentos preexistentes nos indivíduos, ampliam as possibilidades de identificação de potencialidades e de melhoramentos de novos produtos.

\section{Metodologia}

Tendo-se, na seção 2, realizado a primeira etapa de um estudo empírico, que segundo Bêrni e Fernandez (2012), consiste basicamente na exposição do marco conceitual no qual são estabelecidos os conceitos relevantes, as variáveis econômicas que os capturam e o tipo de relação que a teoria sugere existir entre elas, na seção 3 apresentaremos os procedimentos metodológicos típicos da segunda etapa, ou seja, a apresentação da base de dados, a forma como foram calculados os indicadores de aprendizagem e inovação e as características da modelagem econométrica. Além disso, como a subdivisão setorial está baseada em Bittencourt (2012), julgou-se adequado apresentar também aqui os padrões setoriais de aprendizagem, uma vez que sua conformação foi realizada a partir dos mesmos indicadores utilizados neste artigo. Na sequência dessas apresentações, realizadas na subseção 3.1, discutimos procedimentos econométricos na seção 3.2 para, na seção 4, cumprir a última etapa de um estudo empírico típico e analisar os resultados encontrados.

\subsection{Características da base de dados, os indicadores de aprendiza- gem e inovação e os padrões setoriais de aprendizagem}

A identificação de padrões setoriais de aprendizagem foi realizada valendo-se da base de dados da Pesquisa de Inovação Tecnológica - PINTEC (em suas versões I, II e III, relativas aos anos de 2000, 2003 e 2005), com base num recorte setorial definido ao nível dos três dígitos da Classificação Nacional da Atividade Econômica (CNAE). 
O uso da base de dados nesse nível pode ser considerado um fator limitante, não apenas em razão dos graus de liberdade a que estão sujeitos os cálculos econométricos, mas também por considerar-se o comportamento do setor como uma "média" do comportamento de todas as empresas nele incluído. A relevância da separação por conjuntos de setores tem propriedade no apontamento de diferenças intersetoriais relevantes. $O$ quadro abaixo apresenta as informações da PINTEC utilizadas para a construção dos indicadores de aprendizagem. As formas de aprendizagem foram definidas segundo Malerba (1992); Hedberg (1981) e Kim e Nelson (2005), considerando as limitações de mensuração impostas pelas características da PINTEC. Os indicadores combinam fontes de informação utilizadas nos processos de inovação e a importância informada pelas empresas com gastos em atividades inovativas. A construção das combinações procurou considerar a provável atividade inovativa associada ao uso de determinada fonte de informação, como fonte de ideia para a inovação. ${ }^{6}$ Em outras palavras, entende-se que há grande probabilidade de que um insigth surgido, por exemplo, no Departamento de P\&D (fonte de informação) esteja associado a gastos com atividades de $\mathrm{P} \& \mathrm{D}$, conforme relacionado no indicador 1, "aprendizagem via P\&D interna", derivado do "learning by search".

As possibilidades de respostas das empresas inovadoras às questões formuladas pela PINTEC e utilizadas para a formulação dos indicadores são sempre qualitativas: alta, média e baixa ou irrelevante. Esses atributos qualitativos foram transformados em quantitativos para que a técnica estatística pudesse ser utilizada. $O$ procedimento consistiu na substituição dos qualitativos: "alta" "média" e "baixa ou irrelevante", respectivamente, por "1", "0,66" e "0,167". Assim, os indicadores foram formados utilizando-se uma média ponderada da importância atribuída pelo conjunto das empresas inovadoras de cada setor às variáveis selecionadas para a composição desses indicadores.

No que se refere aos indicadores de inovação, também foram utilizadas informações da PINTEC. A pesquisa define dois graus de inovação: para

6 Não se assume que exista correspondência absoluta entre as fontes de ideias e os gastos com atividades de inovação. De fato, ideias surgidas nos Departamentos de P\&D (learning by search) podem ser executadas por meio de gastos com P\&D externo (learning by advanced $S \& T$ ). Contudo, os indicadores assumem que há probabilidade maior de que os gastos sejam realizados nos Departamentos de P\&D da própria empresa, nesse caso.

7 O valor para a especificação qualitativa "baixa ou irrelevante" segue a valoração sequencial das informações alta e média. O valor " 0,176 " é a média entre " 0,33 " e " 0,00 ", valores atribuídos para "baixa" e "irrelevante", respectivamente. 


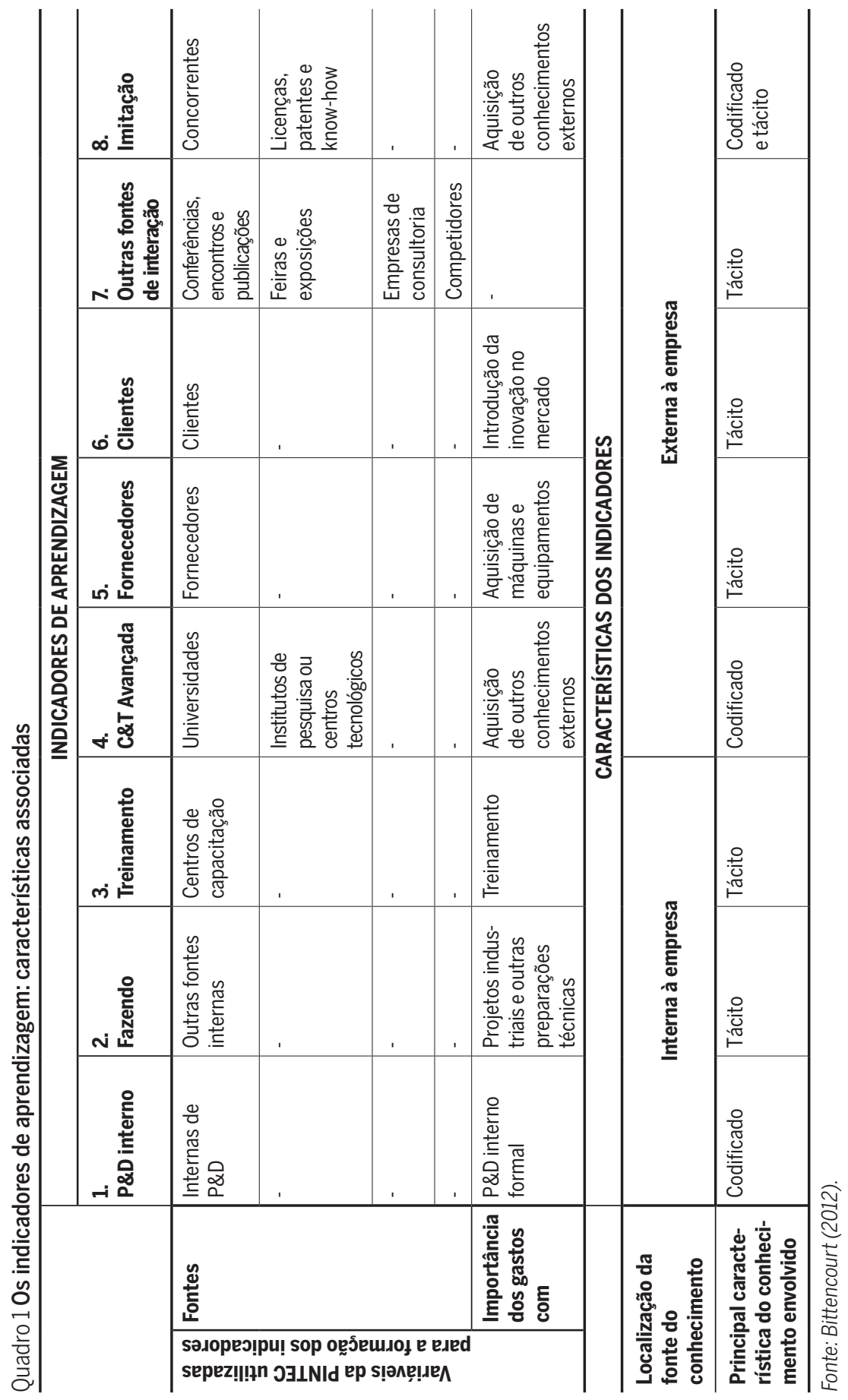


a empresa e para o mercado nacional. Como mostra a Tabela 1, as inovações de grau superior são pouco frequentes, e seu percentual diminuiu desde a primeira pesquisa. A baixa frequência é explicada por fatores que caracterizam o precário desenvolvimento histórico do Sistema Nacional de Inovações brasileiro (Albuquerque, 1996; Viotti, 2002).

Tabela 1 Inovações para a empresa e para o mercado nacional no Brasil

\begin{tabular}{l|r|r|r|r|r|r}
\hline Período & \multirow{2}{*}{$\begin{array}{r}\text { Número de } \\
\text { empresas } \\
\text { inovadoras }\end{array}$} & $\begin{array}{r}\text { Taxa de } \\
\text { inovação* }\end{array}$ & & \% Inovações de produto & \% Inovações de processo \\
\hline $\mathbf{2 0 0 0}$ & 22.698 & 31,52 & 32,28 & 9,27 & 52,22 & 6,23 \\
\hline $\mathbf{2 0 0 3}$ & 28.036 & 33,27 & 37,62 & 5,67 & 54,18 & 2,53 \\
\hline $\mathbf{2 0 0 5}$ & 30.377 & 33,56 & 35,42 & 6,90 & 54,15 & 3,52 \\
\hline
\end{tabular}

Fonte: Elaboração própria com base nas PINTECs 2000, 2003 e 2005.

*Porcentagem das empresas pesquisadas que inovaram no período.

Importante dizer que as inovações para o mercado nacional não podem ser classificadas como inovações radicais. Podem ser (e de fato, na maioria dos casos, o são) inovações incrementais para adaptar à demanda brasileira, produtos já testados em mercados fora do Brasil. São inovações de maior grau do que as classificadas apenas como "para a empresa", uma vez que essas já estão presentes no SNI brasileiro, ${ }^{8}$ ou seja, pelo menos teoricamente, têm maiores chances de se apropriarem do lucro extraordinário do inovador. A fim de medir a intensidade das inovações (para empresa e para o mercado nacional) nos setores, foi calculada a porcentagem de cada um desses graus de inovação em relação ao total de inovações registradas em cada setor, o que define a intensidade de cada grau de inovação em cada um deles. ${ }^{9}$ Cabe observar que o uso dos indicadores resultantes como variáveis dependentes nas análises estatísticas só foi possível por se tratar de uma medida de intensidade, a exemplo dos indicadores de aprendizagem.

8 Ainda que a adaptação de uma inovação lançada fora do Brasil deva ser classificada como difusão ao mercado nacional, neste artigo, para efeito de diferenciação, apenas as inovações para a empresa são denominadas como fruto do processo de difusão.

9 O total das inovações registradas é obtido pela soma das inovações de produto e de processo para a empresa e para o mercado nacional. Trata-se, portanto, das taxas de inovação de produto "para a empresa" e "para o mercado nacional" de cada setor. Assim, o termo "grau da inovação" refere-se a seu alcance, para a empresa ou para o mercado. O termo "intensidades de inovação" refere-se à taxa de inovação de um dos dois graus. 
A análise baseou-se numa caracterização prévia de padrões setoriais de aprendizagem, elaborada por Bittencourt (2012). O uso dos padrões setoriais de aprendizagem como referência setorial se justifica não apenas por considerar características do SNI brasileiro, mas também porque os indicadores utilizados mostrarem-se adequados ao objetivo do artigo.

Como mostra o Quadro 2, a taxonomia contempla quatro grupos de setores. Dentre os Intensivos em Aprendizagem na Esfera da Produção (Padrão 1), sobressaiu a intensidade do uso dos Departamentos de Engenharia de Produção e do chão de fábrica, combinados à interação com fornecedores de insumos, equipamentos ou instrumentos. $\bigcirc$ agrupamento é formado, em grande medida, por setores da indústria alimentícia. Dentre os Intensivos em Aprendizagem a Montante (Padrão 2), foram agrupados setores que se distinguem dos demais por utilizarem pouco mais do que os fornecedores como fontes de aprendizagem em seus processos de inovação. Em grande medida, é formado por aqueles que Pavitt (1984) denominou de "dominados por fornecedores". Os setores Intensivos em Múltiplas Formas de Aprendizagem (Padrão 3) são formados pelos setores mais dinâmicos, cuja aprendizagem envolve $\mathrm{P} \& \mathrm{D}$, as fontes de C\&T, assim como o uso de clientes, de fornecedores e de empresas de consultoria. Os setores Intensivos em Aprendizagem Interna e a Jusante (Padrão 4) suprem diversos outros ramos industriais com conhecimentos resultantes de suas especializações e experiências. Há um conjunto grande de setores "fornecedores especializados" (Pavitt, 1984), cuja aprendizagem é explicada pela combinação de esforços em $\mathrm{P} \& \mathrm{D}$, com o uso dos clientes como fonte de informações.

\subsection{Procedimentos econométricos}

Por utilizar informações das empresas (microdados), grande parte dos trabalhos citados como referência empírica empregam modelos logísticos de estimação da variável dependente, usualmente a inovação de produto (para a empresa ou para o mercado). As variáveis dependentes são discretas e binárias, mais especificamente, "1 ou 0, para inovação ou ausência de inovação", respectivamente. Neste estudo, conforme salientado acima, por trabalhar-se com informações do setor, as variáveis dependentes foram definidas como porcentagens do total de inovação do setor. Em função 
Quadro 2 Os setores que compõem os Padrões Setoriais de Aprendizagem

\begin{tabular}{|c|c|c|c|}
\hline $\begin{array}{l}\text { Padrão } 1 . \\
\text { Setores Intensivos } \\
\text { em Aprendizagem } \\
\text { na Esfera Produtiva }\end{array}$ & $\begin{array}{l}\text { Padrão } 2 . \\
\text { Setores Intensivos } \\
\text { em Aprendizagem } \\
\text { a Montante }\end{array}$ & $\begin{array}{l}\text { Padrão } 3 . \\
\text { Setores Intensivos } \\
\text { em Múltiplas Formas } \\
\text { de Aprendizagem }\end{array}$ & $\begin{array}{l}\text { Padrão } 4 . \\
\text { Setores Intensivos } \\
\text { em Aprendizagem } \\
\text { Interna e a Jusante }\end{array}$ \\
\hline $\begin{array}{l}1 \text { - Carne e de pescado; } \\
2 \text { - Óleos vegetais } \\
\text { animais; } 3 \text { - Laticínios; } \\
4 \text { - Açúcar; } 5 \text { - Café; } \\
6 \text { - Bebida; } 7 \text { - Fiação; } \\
8 \text { - Celulose; } 9 \text { - Álcool; } \\
10 \text { - Cimento; } \\
11 \text { - Ferro-gusa e ferro } \\
\text { liga; } 12 \text { - Tubos; } 13 \text { - Me- } \\
\text { talurgia de não ferrosos; } \\
14 \text { - Produtos diversos } \\
\text { de metal; } 15 \text { - Tratores } \\
\text { e M\&E p/ agricultura; } \\
16 \text { - Máquinas-ferramen- } \\
\text { ta; } 17 \text { - Equip. de energia } \\
\text { elétrica; } 18 \text { - Peças p/ } \\
\text { veículos. }\end{array}$ & 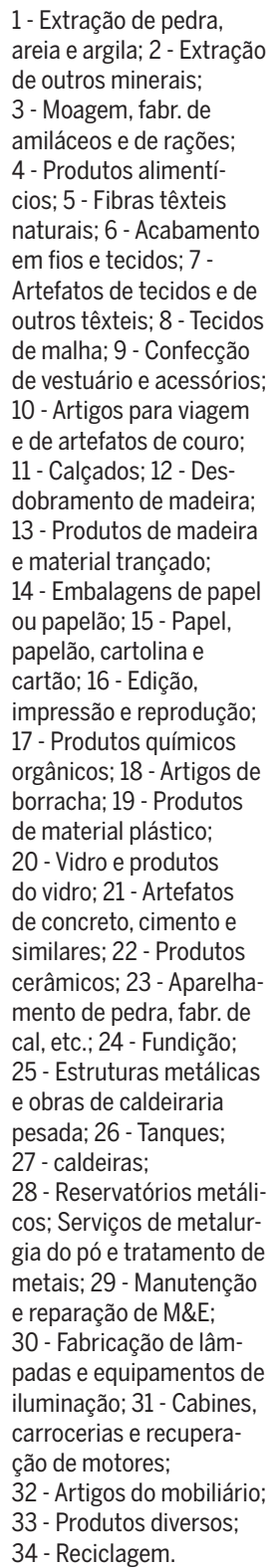 & $\begin{array}{l}1 \text { - Produtos farmacêu- } \\
\text { ticos; } 2 \text { - Defensivos } \\
\text { agrícolas; } 3 \text { - M\&E } \\
\text { para informática e } \\
\text { escritório; } 4 \text { - Fios, cabos } \\
\text { e condutores elétricos } \\
\text { isolados; } 5 \text { - Pilhas, } \\
\text { baterias e acumuladores } \\
\text { elétricos; } 6 \text { - Aparelhos } \\
\text { e equipamentos de } \\
\text { telefonia e radiotelefonia } \\
\text { e de transmissores de } \\
\text { televisão e rádio; } 7 \text { - Apa- } \\
\text { relhos e instrumentos de } \\
\text { medida, teste e controle; } \\
8 \text { - Aparelhos, instrumen- } \\
\text { tos e materiais ópticos, } \\
\text { fotográficos e cinemato- } \\
\text { gráficos; } 9 \text { - Automóveis, } \\
\text { camionetas e utilitários; } \\
10 \text { - Caminhões e ônibus; } \\
11 \text { - Produtos do fumo. }\end{array}$ & $\begin{array}{l}1 \text { - Químicos inorgânicos; } \\
2 \text { - Resinas, elastômeros, } \\
\text { fibras, filamentos artifi- } \\
\text { ciais e sintéticos; } 3 \text { - Tin- } \\
\text { tas, vernizes, esmaltes, } \\
\text { lacas e produtos afins; } \\
4 \text { - Produtos e prepara- } \\
\text { dos químicos diversos; } \\
5 \text { - Artigos de cutelaria, } \\
\text { de serralheria e } \\
\text { ferramentas manuais; } \\
6 \text { - Motores, bombas, } \\
\text { compressores e equipa- } \\
\text { mentos de transmissão; } \\
7 \text { - M\&E de uso geral; } \\
8 \text { - M\&E de usos na extra- } \\
\text { ção mineral e construção; } \\
9 \text { - Outras M\&E de uso } \\
\text { na extração mineral; } \\
10 \text { - Material elétrico para } \\
\text { veículos; } 11 \text { - Fabricação e } \\
\text { reparação de máquinas, } \\
\text { aparelhos e materiais } \\
\text { elétricos; } 12 \text { - Material } \\
\text { eletrônico básico; } \\
13 \text { - Outros equipamentos } \\
\text { de transporte. }\end{array}$ \\
\hline
\end{tabular}

Fonte: Bittencourt (2012). 
da utilização de variáveis dependentes contínuas, sabe-se que os modelos mais apropriados não são os logísticos (Wooldridge, 2006).

Em geral, os estudos empíricos citados no quadro de referência teórico utilizam regressões múltiplas para estimar seus regressores, considerando que, quanto mais variáveis forem incorporadas ao modelo de análise, maior será o montante de variância que poderá ser explicado por ele. Os estudos se valem, normalmente, de informações de mais de 2.000 empresas, o que diminui suas restrições quanto aos graus de liberdade. No estudo exploratório aqui desenvolvido, no entanto, as informações disponíveis restringem-se ao plano setorial, gerando um número restrito de casos. ${ }^{10}$ Neste contexto, os graus de liberdade associados a uma regressão múltipla poderiam gerar problemas, uma vez que, à medida que aumenta o número de variáveis independentes, diminui-se a capacidade de teste do modelo, ou seja, torna-se menor o poder explicativo dos testes de hipótese.

Uma grande preocupação nesse sentido refere-se à presença de multicolinearidade, ${ }^{11}$ revelada por intervalos de confiança muito grandes para os coeficientes e as estatísticas ( $t$ ) muito pequenas. Dessa forma, a significância estatística estaria restrita a coeficientes muito altos e, portanto, seria mais difícil rejeitar a hipótese nula. Além disso, quando dois estimadores (Xs) são altamente e positivamente correlacionados, ou seja, na presença de alto grau de multicolinearidade, a inclinação dos estimadores tenderá a ser alta e negativamente correlacionada em regressões múltiplas. O resultado seria a superestimação de um dos regressores e a subestimação do outro (overfitting ou overtrainning).

Considerando que a multicolinearidade é, fundamentalmente, um problema de grau (quanto maior a correlação, maior o grau de multicolinearidade), procurou-se identificá-la na amostra mediante dois procedimentos:

(i) verificação dos coeficientes de correlação das variáveis independentes. Como se pode observar facilmente nas Tabelas 1, 2, 3 e 4 do Anexo Estatístico, há, de fato, diversos índices de correlação altos, acima de 0,5, e

(ii) observação da mudança de sinal, teoricamente questionável, quando variáveis dependentes são adicionadas ao modelo de regressão múltipla. Tal procedimento também foi realizado e verificou-se, por exemplo, que

10 Especificamente, de 240 para o caso geral, 57 para o Padrão 1, 99 para o Padrão 2, 33 para o Padrão 3, e 51 para o Padrão 4, o que corresponde ao número de setores multiplicados pelo número de períodos considerados (três períodos).

11 Quando as variáveis independentes são fortemente correlacionadas. 
as fontes avançadas de C\&T passavam a ter sinal negativo em regressões múltiplas que consideravam as variáveis dependentes estatisticamente significativas nas regressões simples. Um exemplo foi uma regressão múltipla realizada para o caso geral (todos os setores), utilizando-se a intensidade das inovações de produto para o mercado como variável dependente e a $\mathrm{P} \& \mathrm{D}$, "aprender fazendo", fontes avançadas de C\&T e o uso dos clientes como variáveis independentes.

A partir da verificação da presença de multicolinearidade entre as variáveis independentes, decidiu-se pelo uso de regressões simples para estimar o efeito da variação dos indicadores de aprendizagem (variáveis independentes), na intensidade das inovações de produto para a empresa e para o mercado nacional (variáveis dependentes).

Além da multicolinearidade, os dados apresentaram heteroscedasticidade em diversos casos, como revelado na Tabela 5 do Anexo Estatístico, referente ao teste White. Para corrigir esse problema, utilizou-se o método de mínimos quadrados generalizados (generalized least squared), por representar o melhor estimador não viesado (Greene, 2003; Wooldridge, 2006).

\section{Resultados e discussão}

Esta seção está dividida em duas partes. A primeira discute a associação entre formas de aprendizagem e inovação de produto com base nos resultados econométricos calculados para o conjunto de setores da amostra, ou seja, para a soma dos quatro padrões setoriais de aprendizagem (o que denominamos de "caso geral"). Nesta subseção, além da primeira hipótese, discutem-se características gerais do processo no SNI brasileiro, com especial referência à importância da transmissão de conhecimentos tácitos no processo de aprendizagem e inovação. A segunda seção tem foco em cada um dos padrões setoriais de aprendizagem.

\subsection{Fatores internos e externos de aprendizagem e inovação de produtos: um quadro geral}

Nesta análise, desenvolvida para todos os setores da amostra, "caso geral", pode-se inferir diretamente dos resultados das Tabelas 2 e 3, associações 
significativas de quatro formas de aprendizagem (P\&D, "aprender fazendo", fontes de C\&T e clientes) no caso das "inovações para o mercado nacional" e, apenas dos clientes para "inovações para a empresa".

Tabela 2 Formas de aprendizagem e inovações para o mercado nacional (caso geral)

\begin{tabular}{|c|c|c|c|c|c|c|c|c|c|c|c|c|}
\hline & \multicolumn{3}{|c|}{ P\&D interna } & \multicolumn{3}{|c|}{ Fazendo } & \multicolumn{3}{|c|}{ Treinamento } & \multicolumn{3}{|c|}{$\begin{array}{l}\text { Fontes avançadas } \\
\text { de C\&T }\end{array}$} \\
\hline & Beta & Valor $p$ & Desv. pad & Beta & Valor $p$ & Desv. pad & Beta & Valor $p$ & Desv. pad & Beta & Valor $p$ & Desv. pad \\
\hline Geral & 1,31 & 0,00 & 3,26 & 1,61 & 0,00 & 5,65 & 0,10 & 0,63 & 7,80 & 1,46 & 0,00 & 9,16 \\
\hline \multicolumn{13}{|c|}{ (continuação) } \\
\hline & \multicolumn{3}{|c|}{ Fornecedores } & \multicolumn{3}{|c|}{ Clientes } & \multicolumn{3}{|c|}{$\begin{array}{l}\text { Outras fontes } \\
\text { externas }\end{array}$} & \multicolumn{3}{|c|}{ Imitação } \\
\hline & Beta & Valor $p$ & Desv. pad & Beta & Valor $p$ & Desv. pad & Beta & Valor $p$ & Desv. pad & Beta & Valor $p$ & Desv. pad \\
\hline Geral & $-2,71$ & 0,00 & 5,22 & 1,90 & 0,00 & 5,57 & 0,34 & 0,31 & 8,29 & 0,19 & 0,38 & 6,53 \\
\hline
\end{tabular}

Fonte: Elaboração própria com base no software MatLab.

Tabela 3 Formas de aprendizagem e inovações para a empresa (caso geral)

\begin{tabular}{|c|c|c|c|c|c|c|c|c|c|c|c|c|}
\hline & \multicolumn{3}{|c|}{ P\&D interna } & \multicolumn{3}{|c|}{ Fazendo } & \multicolumn{3}{|c|}{ Treinamento } & \multicolumn{3}{|c|}{$\begin{array}{c}\text { Fontes avançadas } \\
\text { de C\&T }\end{array}$} \\
\hline & Beta & Valor $p$ & Desv. pad & Beta & Valor $p$ & Desv. pad & Beta & Valor $\mathrm{p}$ & Desv. pad & Beta & Valor $\mathrm{p}$ & Desv. pad \\
\hline Geral & 0,05 & 0,39 & 4,32 & $-0,04$ & 0,72 & 6,59 & $-0,07$ & 0,36 & 8,57 & 0,05 & 0,68 & 10,44 \\
\hline \multicolumn{13}{|c|}{ (continuação) } \\
\hline & \multicolumn{3}{|c|}{ Fornecedores } & \multicolumn{3}{|c|}{ Clientes } & \multicolumn{3}{|c|}{$\begin{array}{l}\text { Outras fontes } \\
\text { externas }\end{array}$} & \multicolumn{3}{|c|}{ Imitação } \\
\hline & Beta & Valor $p$ & Desv. pad & Beta & Valor $p$ & Desv. pad & Beta & Valor $\mathrm{p}$ & Desv. pad & Beta & Valor $\mathrm{p}$ & Desv. pad \\
\hline Geral & $-0,45$ & 0,65 & 6,38 & 0,31 & 0,00 & 6,72 & $-0,06$ & 0,60 & 9,14 & 0,02 & 0,84 & 7,19 \\
\hline
\end{tabular}

Fonte: Elaboração própria com base no software MatLab.

Os resultados aproximam-se de Jensen et al. (2007) ao apontarem a combinação de fatores codificados ( $\mathrm{P} \& \mathrm{D}$ interna e $\mathrm{C} \& \mathrm{~T}$ avançada, no nosso caso) com os de caráter tácito ("aprender fazendo" e "aprender com clientes") como elemento potencializador de inovações para o mercado nacional. Também são consistentes com a primeira hipótese do artigo, concernente à combinação de um conjunto maior de formas de aprendizagem para viabilizar inovações de maior grau. Já os resultados das formas de aprendizagem típicas das inovações "para empresa" apontam apenas os 
clientes como fontes relevantes. ${ }^{12}$ A partir disso, entende-se que a difusão de inovações no SNI brasileiro é fenômeno altamente dependente da relação entre produtores e usuários das inovações.

Da diversidade de competências tecnológicas que caracteriza as firmas mais avançadas do SNI brasileiro (pioneiras para o mercado nacional), poder-se-ia esperar um aumento, de um período para o outro, da frequência de firmas engajadas em formas de aprendizagem potencialmente mais virtuosas. No entanto, a Tabela 1 revela frequência estável e pouco expressiva de firmas que inovaram para o mercado nacional (não mais do que $10 \%$ do total). Vários aspectos poderiam ser levantados para explicar o fenômeno. Ainda que especulativamente, entende-se que dificilmente não estariam entre eles: a quantidade limitada de mão de obra capacitada para atividades de $\mathrm{P} \& \mathrm{D}$ em determinadas áreas do conhecimento; os altos custos das atividades de pesquisa; a incerteza associada aos projetos de inovação; a falta de pessoal qualificado nas empresas e nas universidades para estreitar os vínculos entre esses atores; o excesso de burocracia nas universidades para intensificar essa relação, dentre outros. No entanto, parece especialmente relevante o entrave causado pela enraizada prática das firmas brasileiras de adaptar, para a demanda nacional, produtos desenvolvidos em outros SNIs, como apontou Viotti (2002), por exemplo. Essa prática se autorreforça ao não impulsionar rotinas de busca (Nelson; Winter, 1982) mais virtuosas entre as firmas, tornado menos provável o uso intensivo de recursos de $\mathrm{P} \& \mathrm{D}$ e $\mathrm{C} \& \mathrm{~T}$ nas atividades de inovação, no SNI brasileiro.

Com a finalidade de compreender o papel dos clientes na prática de adaptar inovações, enraizada das firmas brasileiras, mas também na baixa frequência de inovações de produto, admitimos partir do pressuposto intuitivo de que os clientes da indústria nacional podem ser caracterizados como de menor nível qualitativo, relativamente aos clientes de firmas inseridas em SNIs mais avançados. Com esse pressuposto, está-se admitindo que limitadas aptidões tecnológicas das firmas demandantes (usuários das inovações) de produtos de outras firmas da indústria brasileira (produtores das inovações) estariam desestimulando processos virtuosos de busca entre os produtores de inovação. Entre as firmas produtoras de produtos finais, o baixo nível de exigência da demanda cuja renda per capita é reconhecidamente inferior às dos países desenvolvidos, estaria deixando de induzir processos

12 Resultados semelhantes foram observados em Caloghirou et al. (2004), Tödling et al. (2008) e Veja-Jurado et al. (2008). 
de inovação mais virtuosos. Como consequência, as redes que se formariam no Brasil seriam qualitativamente inferiores às redes em que se engajam as firmas inovadoras inseridas em SNIs avançados. Segundo Laursen (2011), o perigo de estar envolvido em redes de produção e inovação com clientes pouco exigentes, conservadores e avessos à inovação, reside na busca de novas soluções ao longo de trajetórias estabelecidas, afastando-se das oportunidades que poderiam ser verdadeiramente novas e promissoras.

Se a intuição e a análise decorrente estiverem corretas, uma hipótese para novos trabalhos emerge: não apenas a baixa frequência de inovação para o mercado nacional, mas também a baixa frequência absoluta de inovação de produto do SNI brasileiro teria na qualidade dos clientes um elemento central de sua explicação. Seria um tipo de lock-in, em que os clientes nacionais, por seu baixo nível de exigência/sofisticação, não funcionariam como estimuladores de processos de aprendizado e inovação consistentes. Na maior parte das vezes, induziriam os produtores de inovação a processos que desembocam, no máximo, em "melhoramentos de produtos", o que não pode sequer ser qualificado como inovação incremental, ou mesmo, "para a empresa". Disso deriva-se que a dependência do passado, que restringe os processos de inovação no SNI brasileiro, encontraria na qualidade de seus clientes forte restrição ao melhoramento dos processos de inovação de produto. Uma espécie de camisa de força à aceleração dos avanços tecnológicos.

Por outro lado, mas não menos importante, a proximidade locacional constitui um acelerador da difusão de conhecimentos tácitos por meio, por exemplo, do estabelecimento de códigos locais de comunicação entre produtores e usuários das inovações, reforçando as relações fortes, inclusive de confiança, dentre eles, Lundvall (1988). Por essa razão, entende-se que uma base produtiva brasileira relativamente diversificada serve como apoio aos pouco frequentes processos virtuosos de aprendizagem e inovação verificados.

Em síntese, a densidade de firmas, a diversidade setorial e a proximidade geográfica entre muitos dos atores envolvidos nos processos de aprendizagem e inovação, típicos do SNI brasileiro, contribuem para o surgimento de inovação. Entretanto, a baixa qualidade dos conhecimentos envolvidos nas interações ajudaria a definir a incapacidade das firmas do SNI adentrarem em trajetórias tecnológicas mais promissoras, marcadas por esforços de $P \& D$ e $C \& T$ avançada. 


\subsection{Aprendizagem para a inovação de produto nos padrões seto- riais de aprendizagem}

Nesta seção, a amostra é subdividida e analisada em quatro conjuntos de setores, os padrões setoriais de aprendizagem. Tal subdivisão é adequada porque ressalta aspectos da aprendizagem tecnológica setorial, observados no SNI brasileiro. A análise serve ao objetivo de apontar especificidades nos processos de aprendizagem para inovação de produtos entre os grupos de setores similares. Dentre as especificidades, destaca-se, por exemplos, a significância estatística da P\&D entre os setores Intensivos em Aprendizagem na Esfera Produtiva (Padrão 1) e dos fornecedores e das fontes de imitação entre os setores Intensivos em Aprendizagem Interna e a Jusante (Padrão 4), nas inovações para a empresa. Dentre as inovações para o mercado nacional, o exemplo é o uso das fontes de P\&D e C\&T avançadas, entre os setores Intensivos em Aprendizagem a Montante (Padrão 2).

Os resultados também confirmaram a segunda hipótese da pesquisa, ainda que parcialmente. Apesar de as diferenças entre os padrões terem sido identificadas (confirmando a segunda hipótese), é também inegável a presença do que podemos caracterizar como um "formato básico" dos processos de aprendizagem para produto no Brasil, marcado pelo uso dos clientes para inovações para o mercado e pela combinação do uso dos clientes e dos esforços de P\&D nas inovações para o mercado nacional.

Partindo para a análise de cada agrupamento de setores, verifica-se que, entre os setores Intensivos em Aprendizagem na Esfera Produtiva (Padrão 1), o formato "básico" foi observado. Ou seja, apenas a P\&D interna e os clientes revelaram-se como formas de aprendizado significativas ${ }^{13}$ à introdução de inovações de produto. A especificidade é a significância da $\mathrm{P} \& \mathrm{D}$ interna, para inovações "para a empresa" (Tabela 5). Uma possível explicação é a necessidade de adequação a uma demanda mais exigente,,$^{14}$ talvez pela demanda externa sofisticada de setores como café, pescados, celulose, ferro e outros, assim como pela demanda sofisticada de setores como o de peças para veículos e de máquinas-ferramentas (Quadro 2).

13 A Tabela 1 do Anexo Estatístico aponta correlações significativas entre: o uso das fontes de C\&T, das "outras fontes de aprendizagem", do treinamento e, especialmente, dos fornecedores (que definem o padrão) com as inovações de impacto inferior (para a empresa).

14 Nessa suposição, está implícita a noção de que, nos esforços de P\&D, estariam "embutidos" esforços para a absorção de conhecimentos dos clientes. 
Dentre os setores intensivos em Aprendizagem a Montante (Padrão 2), também o formato básico pode ser verificado. Contudo, a geração das inovações para o mercado nacional é reflexo ainda do "aprender fazendo" e do uso das fontes de C\&T. Considerando as formas típicas de aprendizagem que definem esse conjunto de setores, notadamente marcadas por pouco uso dos Departamentos de P\&D e das fontes de C\&T, entendeu-se que a significância estatística dessas variáveis poderia estar sendo explicada por um pequeno grupo de setores com níveis relativamente altos dos dois indicadores (tanto de aprendizagem como de inovação) e, por outro lado, por um grande grupo de setores em que a correlação direta dos indicadores se dá pela sua baixa intensidade.

Essa impressão foi corroborada com a comparação dos Gráficos 1 e 2, nos quais, estão plotadas a aprendizagem via $\mathrm{P} \& \mathrm{D}$ no eixo " $\mathrm{X}$ " e a intensidade das inovações de produto para o mercado nacional no eixo "Y", para os setores dos Padrões 2 e 3 , respectivamente..$^{15}$ Analisando-se comparativamente, nota-se, no Gráfico 1, referente aos setores Intensivos em Aprendizagem a Montante, (Padrão 2), um conjunto grande de casos (setores) que combinam restritos índices de aprendizagem (entre 0,15 e 0,4$)$ e de inovação (entre 0 e 20) e um grupo menor, mas não irrelevante, de casos que combinam índices relativamente mais expressivos de aprendizagem (entre 0,4 e 0,75) e inovação (entre 20 e 30). Em contraste, no Gráfico 2, referente aos setores marcados pela aprendizagem Intensiva em Múltiplas Fontes (Padrão 3), essas posições claramente se invertem. $O$ menor grupo é aquele que combina níveis mais restritos dos índices de aprendizagem (entre 0,2 e 0,5 ) e inovação (10 e 25), ao passo que o grupo com maior número de casos (setores) combina índices relativamente mais expressivos de aprendizagem em P\&D (0,5 e 0,9) e inovações (entre 20 e 45). De forma sintética, a comparação mostra que, mesmo em um conjunto de setores definidos por pouca intensidade dos esforços de $\mathrm{P} \& \mathrm{D}$, as inovações para o mercado nacional são explicadas por esse tipo de esforço.

Dentre os setores marcados por Múltiplas Formas de Aprendizagem (Padrão 3), a especificidade está no fato de nenhum dos indicadores de

15 Decidiu-se por essa comparação, já que se trata de grupos de setores muito distintos nas formas de aprendizagem. Como visto, os setores do Padrão 2 aprendem quase que exclusivamente com fornecedores, enquanto os agrupados no Padrão 3 aprendem com múltiplas fontes. Os gráficos para os outros setores não foram plotados no artigo, visto que se entendeu que a comparação entre os Padrões 2 e 3 era suficiente para compreender a significância estatística da P\&D como forma de aprendizagem do Padrão 2. 
aprendizagem ter apresentado significância estatística ${ }^{16}$ nas inovações para a empresa. Possivelmente porque nem todas as formas de aprendizagem sejam captadas pela PINTEC, como as tecnologias de reverso, por exemplo. Isso significa que outras formas de aprendizagem podem ajudar a explicar a difusão de inovações no SNI brasileiro, em geral, e, certamente, nos setores mais dinâmicos nas formas de aprender. Já, dentre as inovações para o mercado nacional, a aprendizagem via P\&D interna, combinada ao uso dos clientes, sugere que também, dentre os setores mais dinâmicos, as atividades de $\mathrm{P} \& \mathrm{D}$ podem estar sendo fontes de acesso e exploração do conhecimento dos clientes (Cohen; Levinthal, 1990).

Dentre os setores Intensivos em Aprendizagem Interna e a Jusante (Padrão 4), marcados pela presença sobretudo de setores classificados como "fornecedores especializados", mas também por "baseados em ciência" e "intensivos em escala" (Pavitt, 1984), a aprendizagem com clientes não é a única com associação às inovações "para a empresa". Também os fornecedores e a imitação revelaram relevância. Nesse sentido, pode-se intuir a respeito da relevância dos conhecimentos dos fornecedores de componentes e insumos embutidos nos produtos de fabricantes de fibras sintéticas; tintas e químicos inorgânicos ou de componentes eletrônicos e materiais elétricos para veículos; de máquinas, aparelhos e materiais elétricos em geral; de peças e componentes etc., para processos de inovação. No que tange às inovações de produto para o mercado nacional, apenas a aprendizagem com as fontes avançadas de C\&T mostrou-se significativa. É possível que essa relação seja explicada pelas competências na área das engenharias, acumuladas no interior da estrutura de C\&T brasileira. ${ }^{17} \mathrm{~A}$ não significância das atividades de P\&D interna, nesse caso, sugere que essas podem estar voltadas ao desenvolvimento de inovação de processo, muito relevante nesses setores.

De forma resumida, a análise dos padrões setoriais de aprendizagem aponta as especificidades das formas de aprender que conduzem às inovações de produto, mas também reforçam elementos discutidos na seção 5.1,

16 A Tabela 3 do Anexo Estatístico revela correlações significativas entre o uso dos fornecedores e as inovações de processo para a empresa e para o mercado nacional. Mas também da $\mathrm{P} \& \mathrm{D}$, "aprender fazendo", do treinamento e dos clientes para a inovação de processo para o mercado nacional.

17 Rapini (2007) destacou que aproximadamente $45 \%$ dos grupos de pesquisa brasileiros (inseridos ou não em universidades) que interagiram com a estrutura produtiva são das áreas do conhecimento de "engenharia e de computação". 
sobre o "caso geral". Em primeiro lugar, viu-se que a geração de inovações para o mercado nacional encontra nos conhecimentos codificados (P\&D e C\&T avançada) uma fonte altamente relevante. No caso da P\&D interna, contudo, é combinado aos dos clientes, o que aponta a aprendizagem via $\mathrm{P} \& \mathrm{D}$, teoricamente com maior conteúdo codificado, sendo utilizada como forma de absorver conhecimentos dos clientes, teoricamente com maior conteúdo tácito. ${ }^{18}$ Em segundo lugar, que as inovações para a empresa são explicadas pelo uso de fontes de aprendizagem para transferência de conhecimentos tácitos.

Gráfico 1 Dispersão de inovações para o mercado $(Y)$ e aprendizagem via P\&D interna (X) entre os setores intensivos em aprendizagem a montante (Padrão 2)

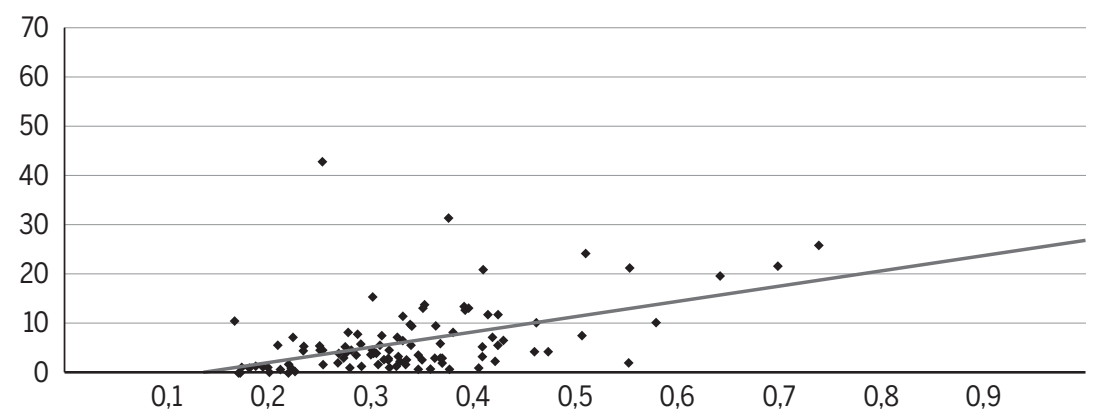

Fonte: Elaboração própria com base no software MatLab.

Gráfico 2 Dispersão de inovações para o mercado $(Y)$ e aprendizagem via P\&D interna (X) entre os setores intensivos em múltiplas formas de aprendizagem (Padrão 3)

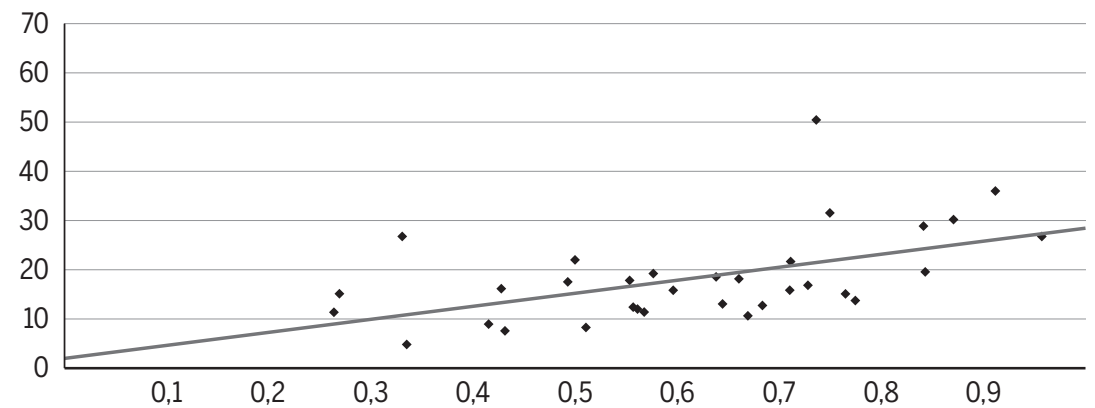

Fonte: Elaboração própria com base no software MatLab.

18 Bittencourt e Giglio (2013) exploram e discutem com maior rigor esse aspecto. 
Do ponto de vista das especificidades setoriais, a análise revelou que diferenças nas formas de aprender para inovar em produto estão em linha com a noção de que os processos diferem entre tipos de setores (Malerba, 1992; Pavitt, 1984). Isso importa porque aponta aos policy makers a necessidade de observar tais diferenças e pode dar base a políticas de inovação mais amplas do que aquelas assentadas exclusivamente em incentivos à $\mathrm{P} \& \mathrm{D}$, por exemplo.

No que se refere à difusão de inovações no interior do SNI (inovações para a empresa), notou-se que elas estão, exclusivamente, associadas ao uso de fontes de aprendizagem para transferência de conhecimentos tácitos. Isso ocorre especificamente no caso dos clientes, tanto para os setores Intensivos em Aprendizagem na Esfera Produtiva (Padrão 1) como para os Intensivos em Aprendizagem a Montante (Padrão 2) ou para os Intensivos em Aprendizagem Interna e a Jusante (Padrão 4), mas também no caso dos fornecedores e das fontes de imitação para os últimos. Da perspectiva do SNI, o destacado papel dos clientes nos processos de difusão, quer de setores produtores de bens de consumo final, quer de outros, cuja demanda é realizada na indústria, reforça o argumento de Lundvall (1988) de que a proximidade geográfica estimula a aprendizagem e a difusão tecnológica, por exemplo, estabelecendo e revigorando relações de confiança entre os agentes. Contudo, o perigo de estar associado a clientes pouco exigentes pode estar dando ênfase a esforços pouco nobres para o desenvolvimento de inovações de maior grau, "para o mercado nacional", como destacou Laursen (2011).

Os resultados desse artigo sugerem que os processos de inovação no Brasil podem estar sendo limitados pela pouca exigência dos clientes nacionais. Estar submetido a eles pode estar gerando um efeito de lock-in, limitador do engajamento em trajetórias tecnológicas mais promissoras. Por essa razão, entende-se que uma política que estimule as exportações brasileiras pode ser decisiva para que os produtores possam interagir com clientes mais sofisticados, capazes de compartilhar informações e conhecimentos sobre designs e técnicas de produção mais avançados, partes de trajetórias tecnológicas mais promissoras. Rhee, Pursell, and Ross-Larson (1984), apud (Blalock; Gertler, 2004) mostraram que esse processo foi decisivo nos períodos iniciais do desenvolvimento sul-coreano, por exemplo.

$\mathrm{O}$ aprendizado que pode emergir do processo interativo com clientes mais sofisticados é um fundamento neoschumpeteriano. Se o mesmo emergir das exportações poderia ser denominado learning by exporting. Baseando-se nessa possibilidade, deriva-se a recomendação de políticas que 
Tabela 4 Resultado das regressões indicadores de aprendizagem e intensidade das inovações de produto para mercado nacional (padrões 1, 2, 3 e 4)

\begin{tabular}{|c|c|c|c|c|c|c|c|c|c|c|c|c|}
\hline & \multicolumn{3}{|c|}{ P\&D interna } & \multicolumn{3}{|c|}{ Fazendo } & \multicolumn{3}{|c|}{ Treinamento } & \multicolumn{3}{|c|}{$\begin{array}{c}\text { Fontes avançadas } \\
\text { de C\&T }\end{array}$} \\
\hline & Beta & Valor $p$ & Desv.pad & Beta & Valor $p$ & Desu. pad & Beta & Valor $p$ & Desv. pad & Beta & Valor $p$ & Desv. pad \\
\hline Padrão 1 & 0,60 & 0,09 & 7,32 & 0,87 & 0,23 & 9,90 & $-0,58$ & 0,30 & 14,87 & $-0,74$ & 0,46 & 18,68 \\
\hline Padrão 2 & 1,68 & 0,00 & 5,79 & 1,57 & 0,03 & 8,72 & 0,64 & 0,21 & 11,66 & 1,51 & 0,07 & 13,31 \\
\hline Padrão 3 & 0,90 & 0,00 & 7,89 & 0,75 & 0,22 & 16,36 & 0,12 & 0,80 & 22,54 & 0,07 & 0,91 & 23,13 \\
\hline Padrão 4 & 0,35 & 0,27 & 11,69 & $-0,04$ & 0,94 & 16,55 & $-0,27$ & 0,36 & 18,72 & 0,79 & 0,09 & 23,51 \\
\hline \multicolumn{13}{|c|}{ (continuação) } \\
\hline & \multicolumn{3}{|c|}{ Fornecedores } & \multicolumn{3}{|c|}{ Clientes } & \multicolumn{3}{|c|}{$\begin{array}{l}\text { Outras fontes } \\
\text { externas }\end{array}$} & \multicolumn{3}{|c|}{ Imitação } \\
\hline & Beta & Valor $p$ & Desv. pad & Beta & Valor $p$ & Desu. pad & Beta & Valor $p$ & Desu. pad & Beta & Valor $p$ & Desv. pad \\
\hline Padrão 1 & $-2,96$ & 0,42 & 9,61 & 2,19 & 0,00 & 12,01 & $-0,97$ & 0,18 & 12,52 & $-0,33$ & 0,48 & 10,94 \\
\hline Padrão 2 & $-1,35$ & 0,20 & 9,30 & 2,48 & 0,00 & 7,13 & 0,80 & 0,30 & 11,51 & 0,23 & 0,62 & 8,55 \\
\hline Padrão 3 & $-0,77$ & 0,10 & 12,36 & 1,04 & 0,05 & 16,14 & $-0,30$ & 0,63 & 21,43 & 0,26 & 0,41 & 12,76 \\
\hline Padrão 4 & $-2,06$ & 0,14 & 11,82 & $-0,43$ & 0,38 & 18,03 & $-0,07$ & 0,88 & 20,26 & $-0,89$ & 0,01 & 19,77 \\
\hline
\end{tabular}

Fonte: Elaboração própria com base no software MatLab.

Tabela 5 Resultado das regressões, indicadores de aprendizagem e intensidade das inovações de produto para a empresa (padrões 1, 2, 3 e 4)

\begin{tabular}{|c|c|c|c|c|c|c|c|c|c|c|c|c|}
\hline & \multicolumn{3}{|c|}{ P\&D interna } & \multicolumn{3}{|c|}{ Fazendo } & \multicolumn{3}{|c|}{ Treinamento } & \multicolumn{3}{|c|}{$\begin{array}{l}\text { Fontes avançadas } \\
\text { de C\&T }\end{array}$} \\
\hline & Beta & Valor $p$ & Desv. pad & Beta & Valor $p$ & Desu. pad & Beta & Valor $p$ & Desu. pad & Beta & Valor $p$ & Desv. pad \\
\hline Padrão 1 & 0,28 & 0,04 & 10,54 & 0,13 & 0,66 & 14,58 & $-0,34$ & 0,11 & 21,39 & $-0,77$ & 0,04 & 26,32 \\
\hline Padrão 2 & 0,06 & 0,54 & 9,40 & $-0,32$ & 0,38 & 23,39 & $-0,15$ & 0,27 & 16,69 & 0,09 & 0,70 & 19,31 \\
\hline Padrão 3 & $-0,52$ & 0,01 & 11,85 & $-0,39$ & 0,38 & 23,39 & $-0,21$ & 0,52 & 31,68 & 0,34 & 0,43 & 32,39 \\
\hline Padrão 4 & $-0,03$ & 0,89 & 12,63 & 0,00 & 1,00 & 17,67 & 0,07 & 0,67 & 20,12 & $-0,13$ & 0,66 & 25,69 \\
\hline \multicolumn{13}{|c|}{ (continuação) } \\
\hline & \multicolumn{3}{|c|}{ Fornecedores } & \multicolumn{3}{|c|}{ Clientes } & \multicolumn{3}{|c|}{$\begin{array}{l}\text { Outras fontes } \\
\text { externas }\end{array}$} & \multicolumn{3}{|c|}{ Imitação } \\
\hline & Beta & Valor $p$ & Desv. pad & Beta & Valor $p$ & Desu. pad & Beta & Valor $p$ & Desu. pad & Beta & Valor $p$ & Desv. pad \\
\hline Padrão 1 & $-0,97$ & 0,00 & 14,49 & 0,50 & 0,08 & 18,59 & $-0,59$ & 0,03 & 17,79 & $-0,15$ & 0,40 & 15,92 \\
\hline Padrão 2 & $-0,66$ & 0,08 & 17,36 & 0,35 & 0,02 & 11,07 & $-0,08$ & 0,71 & 16,52 & $-0,13$ & 0,31 & 12,16 \\
\hline Padrão 3 & $-0,59$ & 0,08 & 17,36 & $-0,27$ & 0,49 & 23,96 & 0,54 & 0,21 & 29,67 & $-0,01$ & 0,95 & 18,24 \\
\hline Padrão 4 & 0,49 & 0,06 & 15,68 & 0,45 & 0,08 & 18,90 & $-0,16$ & 0,53 & 21,54 & 0,36 & 0,09 & 21,83 \\
\hline
\end{tabular}

Fonte: Elaboração própria com base no software MatLab. 
estimulem de forma consistente o engajamento da indústria na atividade de exportação. Nesse sentido, é possível articular esse tipo de recomendação à proposta de uma política macroeconômica alinhada com as exigências do processo de desenvolvimento, conforme proposto por Bresser, (2007). O learning by exporting parece ser um fundamento neoschumpeteriano à macroeconomia-estruturalista do desenvolvimento de Bresser-Pereira (2007).

Como elemento final dessa discussão vale ressaltar que uma política cambial favorável à inserção exportadora teria impactos positivos à ampliação da participação da estrutura produtiva brasileira nas cadeias globais de valor (Gereffi, 2005). Nesse sentido, o trabalho de Schimitz (2006) é um exemplo de como essa inserção pode limitar, ao invés de ampliar, tanto a construção de capacitações das firmas como o aprendizado na rede local. Não obstante, deve-se considerar que a capacidade de adicionar valor à cadeia por qualquer empresa pode mudar com o tempo, dependendo de seus esforços em torno da construção de competências (Gomes, 2003; Lema; Quadros; Schmitz, 2015), e, é claro, da sofisticação dos recursos disponíveis no SNI em que está inserida.

\section{Conclusão}

O artigo revelou duas características dos processos de aprendizagem para inovação de produto, típicas do SNI brasileiro. As inovações para o mercado nacional são frutos do uso e, possivelmente, da combinação de conhecimentos tácitos e codificados, ao passo que a difusão de inovações (inovações para a empresa) deriva de processos de aprendizagem envolvendo conhecimentos tácitos e externos à firma, sobretudo absorvido dos clientes. Esse resultado ressalta a importância da interação produtor-usuário nos processos de aprendizagem e inovação, destacada primeiramente por Lundval (1988), assim como da qualidade dos clientes nesse processo, lembrada em Laursen (2011) e Blalock e Gertler (2004).

Da perspectiva da interpretação dos fatores que explicam a restrita frequência de inovações de produto pelas firmas do SNI brasileiro, a pesquisa, os resultados e as análises derivadas representam avanço na literatura disponível ao permitirem levantar a hipótese de que um tipo de lock-in estaria tendo lugar na dinâmica de interações entre produtores e usuários 
brasileiros de inovações. Detalhadamente, os baixos níveis de sofisticação da demanda, explicados pelos restritos níveis de aptidão tecnológica dos clientes intermediários (industriais) e de renda per capita dos consumidores finais, podem estar representando uma "camisa de força" ao engajamento em trajetórias tecnológicas promissoras.

Do ponto de vista do que se vislumbra como aprofundamento de pesquisa, derivado da hipótese acima, ressaltam-se três linhas: (i) identificar e analisar as características dos clientes que atuam como estimuladores da implementação de inovações de maior grau; (ii) identificar e analisar as características do tipo de interação que ocorre entre esses atores; e (iii) identificar e analisar a associação dos clientes com produtores na geração e na difusão de inovações de SNIs mais desenvolvidos.

Para ações de política, ressaltamos duas implicações. A primeira refere-se à importância de uma base produtiva diversificada e qualificada para a formação de arranjos interativos e cooperativos capazes de intensificar o processo de geração e difusão de conhecimentos relevantes e, com isso, enraizar conhecimentos tácitos que sustentem a competitividade nacional em trajetórias tecnológicas promissoras. A relevância de estratégias de política nesse sentido foi ressaltada, por exemplo, em Cimoli et al. (2007), ao argumentarem que os diferenciais nos níveis de conhecimentos tácitos resumiriam grande parte das vantagens dos países desenvolvidos. Nessa direção, a importância apontada para os fluxos de informação com clientes reforça a dimensão demand-side das políticas de inovação, inclusive através da mobilização de compras públicas visando estimular a intensificação de esforços inovativos, conforme evidenciado pela comparação de diversas experiências internacionais (Lember; Kattel; Kalvet, 2014)

A terceira é de que políticas capazes de diversificar as exportações brasileiras poderiam potencializar as atividades de inovação, por exporem as rotinas e a construção de competências das firmas exportadoras às exigências mais sofisticadas dos novos clientes (tanto consumidores finais, como industriais com maiores capacitações tecnológicas), gerando o learning by exporting. Nesse sentido, parece plausível aceitar que uma política cambial que estimule as exportações possa representar um incentivo não desprezível à inserção em cadeias globais de valor e que, com o tempo, a capacidade de agregação de valor pela firma nacional mude/melhore. Nesse caso, os argumentos macroeconômicos de Bresser-Pereira (2007), que justificariam a institucionalização de uma política de desvalorização cambial (em relação 
à prática da última década, pelo menos), encontrariam na qualidade dos clientes de SNIs mais desenvolvidos e no learning by exporting derivado da interação com os mesmos, o micro fundamento neoschumpeteriano consistente. A recomendação alinha-se a perspectiva sistêmica, já que tanto as formas das interações como o ambiente macroeconômico importam à consistência dos processos de aprendizagem e inovação (Caraça et al., 2009).

Finalmente, destacamos o caráter exploratório dessa investigação, e a confrontação dos resultados obtidos com estudos que utilizam a empresa como unidade de avaliação certamente seria muito proveitosa. Ainda que muitos setores tenham entrado na análise, a base de dados ao nível do setor é um limitante, por resumir o comportamento das firmas de um setor a uma "média" e por representar menores graus de liberdade nas regressões. A consequência é a necessidade de certa cautela na generalização dos resultados. Nesse sentido, a possibilidade de uso dos microdados (dados ao nível da empresa) apenas na sede do órgão de estatísticas que produz essas informações, o IBGE, no Rio de Janeiro, representa um entrave ao desenvolvimento de pesquisas mais robustas. A possibilidade de uso da base de dados nas sedes regionais da instituição, espalhadas pelo território nacional, é a sugestão.

\section{Referências}

AHUJA, G.; KATILA, R. Technological acquisitions and the innovation performance of acquiring firms: a longitudinal study. Strategic Management Journal, 20, p. 351-374, 2001.

ALBUQUERQUE, E. M. Sistema Nacional de Inovações no Brasil: Uma análise introdutória a partir dos dados disponíveis sobre ciência e a tecnologia. Revista de Economia Política, vol. 16, n. 3,(63), p. 56-72, jul.-set., 1996

BELL, M.; PAVITT, K. The development of technological capabilities. In: UL AQUE, I.; BELL, M.; DAHLMAN, C; LALL, S.; PAVITT, K. Trade, technology and international competitiveness. Washington, DC: The World Bank, 1995. p. 69-101.

BÊRNI, D. D. Á.; FERNANDEZ, B. P. M.. Métodos e técnicas de pesquisa-modelando as ciências empresariais. São Paulo: Saraiva. 2012.

BITTENCOURT, P. F. Padrões Setoriais de Aprendizagem: Uma análise exploratória de dados da PINTEC. Revista Brasileira de Inovação, v. 11, p. 37-68, 2012.

BITTENCOURT, P. F; GIGLIO, R. An empirical analysis of technology absorption capacity of the Brazilian industry. Cepal Review, 111, Dec., 2013.

BLALOCK, G.; GERTLER, P. J. Learning from exporting revisited in a less developed setting. Journal of Development Economics, v. 75, n. 2, p. 397-416, 2004. 
BRESCHI, S.; MALERBA, F.; ORSENIGO, L. Technological regimes and schumpeterian patterns of innovation. Economic Journal, v. 110, n. 436, p. 388-410, 2000.

BRESSER-PEREIRA, L. C. Macroeconomia da estagnação: Crítica da ortodoxia convencional no Brasil pós-1994. São Paulo: Ed. 34, 2007.

CALOGHIROU, Y.; KASTELLI, I.; TSAKANIKAS, A. Internal capabilities and external knowledge sources: Complements or substitutes for innovative performance? Technovation, Elsevier,vol. 24, p. 29-39, 2004.

CARAÇA, J.; LUNDVALL, B. A.; MENDONÇA, S. The changing role of science in the innovation process: From queen to cinderella? Technological Forecasting and Social Change, vol. 76, n. 6, p. 861-867, 2009.

CIMOLI, M.; DOSI, G.; NELSON, R.; STIGLITZ, J. et al. Instituições e políticas moldando o desenvolvimento industrial: Uma nota introdutória. Revista Brasileira de Inovação, Rio de Janeiro, v. 6, n. 1, p. 55-85, jan./jun. 2007.

COHEN, W. M.; LEVINTHAL, D. A. Innovation and learning: The two faces of R\&D. The Economic Journal, v. 99 (Sept.), p. 569-596, 1989.

COHEN, W. M.; LEVINTHAL, D. A. Absorptive capacity: A new perspective of learning and innovation. Administrative Science Quarterly, 35, p. 128-152, Mar. 1990.

DOSI, G. Sources, procedures, and microeconomic effects of innovation. Journal of Economic Literature 26, p. 1120-1171, 1988.

EDQUIST, C. Final remarks: Reflections on the systems of innovation approach. Science and Public Policy, vol. 36, n. 6, p. 485-489, Dec., 2004.

FREEMAN, C. Technology gaps, international trade and the problems of smaller and less developed economies, chapter 3. In: FREEMAN. C.; LUNDVALL, B-A. Small Countries Facing the Technological Revolution, Pinter, p. 67-84, 1988.

GEREFFI, G.; HUMPHREY, J.; STURGEON, T. The governance of global value chains. Review of International Political Economy, 12(1), 78-104, 2005.

GOMES, R. A internacionalização das atividades tecnológicas pelas empresas transnacionais: elementos de organização industrial da economia da inovação. Tese (Doutorado) - IE/ Unicamp, 2003.

GREENE, W. H. Econometric Analysis. Prentice Hall. 5th ed., 2003.

HEDBERG, B. How organizations learn and unlearn. In: NYSTROM, P.; STARBUCK, W. H. Handbook of Organizational Design, v. 1, Cambridge University Press, London, 1981.

IMAI, K.; BABA, Y. Systemic innovation and cross-border networks, transcending markets and hierarchies to create a new techno-economic system. In: OECD. Technology and Productivity: The challenge for economic policy, Paris, p. 389-405, 1991.

JAWORSKI, B. J.; KOHLI, A. K. Market orientation: Antecedents and consequences. Journal of Marketing, 57, p. 53-70, 1993.

JENSEN, M. B.; JOHNSON, B.; LORENZ, E.; LUNDVALL, B. A. Forms of knowledge and modes of innovation. Research Policy, n. 36, p. 680-693, 2007.

KIM, L.; NELSON, R. R. Tecnologia, aprendizado e inovação. Campinas. Editora da Unicamp. 2005. 
LAURSEN, K. User-producer interaction as a driver of innovation: Costs and advantages in an open innovation model. Science and Public Policy, vol. 38, n. 9, p. 713-723, Nov. 2011.

LEMBER, V.; KATTEL, R.; KALVET, T. (Eds). Public Procurement, Innovation and Policy: International Perspectives, 311 pp, Springer-Verlag Berlin Heidelberg, 2014

LEMOS, M. B.; SANTOS, F.; CROCCO, M.. Condicionantes territoriais das aglomerações industriais sob ambientes periféricos. In: DINIZ, C. C.; LEMOS, M. B. Economia e Território. Belo Horizonte: Ed. UFMG, 2005.

LEMA, R.; QUADROS, R.; SCHMITZ, H. Reorganising global value chains and building innovation capabilities in Brazil and India. Research Policy 44, p. 1376-1386, 2015.

LI, I.; VANHAVERBEKE, W. The effects of inter-industry and country difference in supplier relationships on pioneering innovations. Technovation, vol. 29, p. 843-858, 2009.

LUNDVALL, B. A. Innovation as an interactive process: From user-producer interaction to the national system of innovation. In: DOSI, G.; FREEMAN, C; NELSON, R.; SILVERBERG, G.; SOETE, L. (Ed.). Technical Change and Economic Theory. London: Pinter Publishers, p. 349-369, 1988.

LUNDVALL, B. A. National innovation systems-analytical concept and development tool. Industry and innovation, 14(1), 95-119, 2007.

MALERBA, F. Learning by firms and incremental technical change. The Economic Journal, p. 845-859, 1992.

MUROVEC, N.; PRODAN, I. Absorptive capacity, its determinants, and influence on innovation output: Cross-cultural validation of the structural model. Technovation, 29, Ed. Elsevier, p.859-872, 2009.

NELSON, R. Why do firms differ and how does it matter. Strategic Management Journal, 12, p. 61-74, 1991.

NELSON, R.; WINTER, S. G. An evolutionary theory of economic change. USA. Harvard U. P, 1982.

NIETO, M. J.; SANTAMARIA, L. The importance of diverse collaborative networks for the novelty of product innovation. Technovation, v. 27, p. 367-377, 2007.

PAVITT, K. Sectoral patterns of technical change: Towards a taxonomy and a theory. Research Policy, number 13 (6), p. 343-373, 1984.

RAPINI, M. Interação Universidade-Empresa no Brasil: Evidências do diretório dos grupos de pesquisa no Brasil. Estudos Econômicos, v. 37, n. 2, p. 212-233, 2007.

SCHIMITZ, H. Learning and earning in global garment and footwear chains. The European Journal of Development Research, 18(4), 546-571, 2006

SUZIGAN, W.; RAPINI, M.; ALBUQUERQUE, E. M. A changing role for universities in the periphery. Textos para Discussão td. 240, Cedeplar, Universidade Federal de Minas Gerais, 2011.

TÖDTLING, F.; LEHNER, P.; KAUFFMAN, A. Do different types of innovation rely on specific kinds of knowledge interactions? Technovation, vol. 29, p. 59-71, 2009.

TSAI, R. K.; WANG, J. External technology sourcing and innovation performance in LMT sectors: An analysis based on the Taiwanese Technological Innovation Survey. Research Policy, Elsevier, vol. 38, p. 518-526, 2009.

VEGA-JURADO, J. V.; GRACIA, A. G.; LUCIO, I. F.; HENRÍQUEZ, L. M. The effect of exter- 
nal and internal factors on firms'product innovation. Research Policy, 37, p. 616-632, 2008.

VIOTTI, E. B. National Learning Systems - A new approach on technological change in late industrializing economies and evidences from the cases of Brazil and South Korea. Technological Forecasting and Social Change, n. 69, p. 653-680, 2002.

Von HIPPEL, E. The source of innovation. Oxford University Press, New York, 1988.

Von HIPPEL, E.; THOMKE, S.; SONNACK, M. Creating breakthroughs at 3 M. Harvard Business Review 77, p. 47-57, 1999.

WOOLDRIDGE, J. M. Introductory Econometrics: A modern approach. Thomson - South West. 3rd. ed., 2006.

\section{Sobre os autores}

Pablo Felipe Bittencourt - pablofelipe.bittencourt@gmail.com Universidade Federal de Santa Catarina, Florianópolis, SC.

Jorge Nogueira de Paiva Britto - jbrit@terra.com.br

Programa de Pós-Graduação em Economia da UFF, Niterói, RJ.

RicardoGiglio-rgiglio@gmail.com

Christian-Albrechts-Universitaet zu Kiel, Kiel, Alemanha.

Os autores agradecem aos pareceristas anônimos da revista Nova Economia pela leitura detalhada e comentários pertinentes.

\section{Sobre o artigo}

Recebido em 15 de abril de 2013. Aprovado em 18 de fevereiro de 2015 


\section{ANEXOs}

\section{Anexo Estatístico I}

Prod. Emp = Inovação do produto para a empresa;

Prod. Merc = Inovação do produto para o mercado;

Proc. Emp. = Inovação do processo para a empresa;

Proc. Merc = Inovação do processo para a indústria.

Tabela A1 Padrão 1 - Índice de correlação de Pearson para o Padrão Setorial de Aprendizagem 1 (método BootStrap)

\begin{tabular}{|c|c|c|c|c|c|c|c|c|c|c|c|c|}
\hline & \multicolumn{12}{|c|}{ COEFICIENTE DE PEARSON } \\
\hline & 홀 흘 & ठ்่ & : 홀 & 它 & ة & 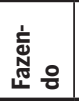 & ๖ & 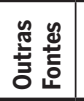 & 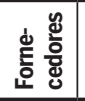 & 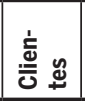 & 产 & 茞突 \\
\hline \multicolumn{13}{|l|}{ Prod. Emp. } \\
\hline Prod. Merc & $-0,173$ & & & & & & & & & & & \\
\hline Proc. Emp. & $-0,617$ & $-0,578$ & & & & & & & & & & \\
\hline Proc. Merc & $-0,334$ & 0,335 & $-0,322$ & & & & & & & & & \\
\hline P\&D Interna & 0,272 & 0,225 & $-0,497$ & 0,320 & & & & & & & & \\
\hline Fazendo & 0,062 & 0,263 & $-0,214$ & 0,159 & 0,365 & & & & & & & \\
\hline C\&T Avançada & $-0,273$ & $-0,102$ & 0,229 & 0,159 & $-0,071$ & 0,406 & & & & & & \\
\hline Outras Fontes & $-0,284$ & $-0,182$ & 0,406 & $-0,136$ & $-0,303$ & 0,245 & 0,794 & & & & & \\
\hline Fornecedores & $-0,369$ & $-0,439$ & 0,601 & $-0,066$ & $-0,151$ & 0,293 & 0,502 & 0,522 & & & & \\
\hline Clientes & 0,234 & 0,403 & $-0,483$ & 0,112 & 0,389 & 0,061 & 0,055 & 0,006 & $-0,152$ & & & \\
\hline Treinamento & $-0,214$ & $-0,144$ & 0,259 & 0,022 & 0,038 & 0,106 & 0,481 & 0,334 & 0,563 & $-0,063$ & & \\
\hline Imitação & $-0,115$ & $-0,097$ & 0,171 & $-0,038$ & $-0,038$ & 0,030 & 0,367 & 0,292 & 0,304 & 0,220 & 0,511 & \\
\hline
\end{tabular}

Fonte: Elaboração própria. 
Tabela A2 Índice de correlação de Pearson para o Padrão Setorial de Aprendizagem 2 (método BootStrap)

\begin{tabular}{|c|c|c|c|c|c|c|c|c|c|c|c|c|}
\hline & \multicolumn{12}{|c|}{ COEFICIENTE DE PEARSON } \\
\hline & 홍 & 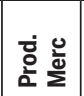 & 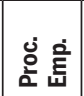 & ن் & ฆ & 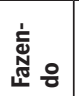 & ๖す & 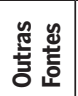 & 离 & 㝘 & 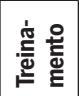 & 亩突 \\
\hline \multicolumn{13}{|l|}{ Prod. Emp. } \\
\hline Prod. Merc & $-0,152$ & & & & & & & & & & & \\
\hline Proc. Emp. & $-0,596$ & $-0,639$ & & & & & & & & & & \\
\hline Proc. Merc & $-0,371$ & 0,481 & $-0,357$ & & & & & & & & & \\
\hline P\&D Interna & 0,061 & 0,477 & $-0,503$ & 0,459 & & & & & & & & \\
\hline Fazendo & $-0,170$ & 0,212 & $-0,094$ & 0,290 & 0,090 & & & & & & & \\
\hline C\&T Avançada & 0,038 & 0,177 & $-0,229$ & 0,248 & 0,467 & 0,199 & & & & & & \\
\hline Outras Fontes & $-0,037$ & 0,103 & $-0,053$ & 0,062 & 0,269 & 0,136 & 0,551 & & & & & \\
\hline Fornecedores & $-0,349$ & $-0,127$ & 0,387 & $-0,064$ & $-0,155$ & 0,062 & $-0,137$ & 0,093 & & & & \\
\hline Clientes & 0,233 & 0,445 & $-0,525$ & 0,195 & 0,457 & 0,193 & 0,338 & 0,325 & $-0,183$ & & & \\
\hline Treinamento & $-0,110$ & 0,125 & 0,001 & 0,046 & 0,227 & 0,257 & 0,306 & 0,342 & 0,262 & 0,221 & & \\
\hline Imitação & $-0,102$ & 0,049 & 0,036 & 0,050 & 0,183 & 0,043 & 0,149 & 0,059 & 0,131 & 0,262 & 0,299 & \\
\hline
\end{tabular}

Fonte: Elaboração própria.

Tabela A3 Índice de correlação de Pearson para o Padrão Setorial de Aprendizagem 3 (método BootStrap)

\begin{tabular}{|c|c|c|c|c|c|c|c|c|c|c|c|c|}
\hline & \multicolumn{12}{|c|}{ COEFICIENTE DE PEARSON } \\
\hline & 홓 & țं 논 & ச் 㒸 & 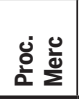 & ‡ & 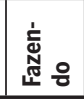 & 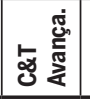 & 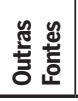 & 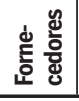 & 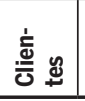 & 突 웧 & 宣穿 \\
\hline \multicolumn{13}{|l|}{ Prod. Emp. } \\
\hline Prod. Merc & $-0,480$ & & & & & & & & & & & \\
\hline Proc. Emp. & $-0,580$ & $-0,327$ & & & & & & & & & & \\
\hline Proc. Merc & $-0,331$ & 0,162 & $-0,221$ & & & & & & & & & \\
\hline P\&D Interna & $-0,424$ & 0,524 & $-0,149$ & 0,453 & & & & & & & & \\
\hline Fazendo & $-0,156$ & 0,214 & $-0,126$ & 0,285 & 0,587 & & & & & & & \\
\hline C\&T Avançada & 0,142 & 0,021 & $-0,256$ & 0,179 & 0,372 & 0,679 & & & & & & \\
\hline Outras Fontes & 0,220 & $-0,086$ & $-0,086$ & $-0,199$ & $-0,008$ & 0,472 & 0,596 & & & & & \\
\hline Fornecedores & $-0,304$ & $-0,284$ & 0,393 & 0,363 & 0,311 & 0,393 & 0,203 & 0,171 & & & & \\
\hline Clientes & $-0,122$ & 0,326 & $-0,304$ & 0,400 & 0,582 & 0,585 & 0,352 & 0,045 & 0,345 & & & \\
\hline Treinamento & $-0,115$ & 0,046 & 0,028 & 0,139 & 0,368 & 0,565 & 0,511 & 0,501 & 0,635 & 0,444 & & \\
\hline Imitação & $-0,012$ & 0,147 & $-0,162$ & 0,130 & 0,167 & 0,307 & 0,110 & 0,248 & 0,278 & 0,446 & 0,338 & \\
\hline
\end{tabular}

Fonte: Elaboração própria. 
Tabela A4 Índice de correlação de Pearson para o Padrão Setorial de Aprendizagem 4 (método BootStrap)

\begin{tabular}{|c|c|c|c|c|c|c|c|c|c|c|c|c|}
\hline & \multicolumn{12}{|c|}{ COEFICIENTE DE PEARSON } \\
\hline & 홀 흘 & 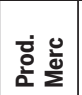 & 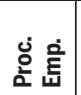 & 广் & 잉 혼 & 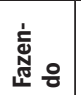 & ๖ & 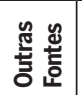 & 헝 흥 & 它 & $\begin{array}{l}\text { 혼 윻 } \\
\text { 힐 }\end{array}$ & 它 \\
\hline \multicolumn{13}{|l|}{ Prod. Emp. } \\
\hline Prod. Merc & $-0,551$ & & & & & & & & & & & \\
\hline Proc. Emp. & 0,009 & $-0,573$ & & & & & & & & & & \\
\hline Proc. Merc & $-0,524$ & 0,256 & $-0,602$ & & & & & & & & & \\
\hline P\&D Interna & $-0,020$ & 0,156 & $-0,599$ & 0,563 & & & & & & & & \\
\hline Fazendo & $-0,001$ & $-0,010$ & 0,095 & $-0,099$ & $-0,190$ & & & & & & & \\
\hline C\&T Avançada & $-0,062$ & 0,223 & $-0,327$ & 0,323 & 0,335 & 0,315 & & & & & & \\
\hline Outras Fontes & $-0,090$ & $-0,022$ & 0,037 & 0,073 & 0,151 & 0,053 & 0,531 & & & & & \\
\hline Fornecedores & 0,259 & $-0,629$ & 0,703 & $-0,465$ & $-0,402$ & 0,065 & $-0,157$ & 0,109 & & & & \\
\hline Clientes & 0,224 & $-0,123$ & 0,036 & $-0,156$ & 0,008 & 0,089 & 0,280 & 0,173 & 0,324 & & & \\
\hline Treinamento & 0,060 & $-0,131$ & 0,186 & $-0,150$ & $-0,093$ & 0,278 & 0,448 & 0,406 & 0,237 & 0,196 & & \\
\hline Imitação & 0,238 & $-0,345$ & 0,028 & 0,058 & 0,132 & $-0,034$ & 0,127 & 0,131 & 0,321 & 0,373 & 0,200 & \\
\hline
\end{tabular}

Fonte: Elaboração própria.

Tabela A5 Resultados do Teste White

\begin{tabular}{|c|c|c|c|c|c|c|c|c|c|}
\hline \multicolumn{10}{|c|}{ RESULTADOS DO TESTE WHITE } \\
\hline & & ఖ & 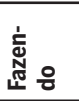 & 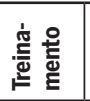 & ๒す心 & 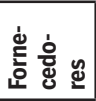 & 㝘 & 沍突 & 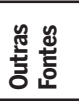 \\
\hline \multirow{2}{*}{ Padrão 1} & Prod. Merc & 0,560 & 0,444 & 0,561 & 0,698 & 0,360 & 0,801 & 0,454 & 0,567 \\
\hline & Prod. Empr & 0,811 & 0,136 & 0,768 & 0,668 & 0,984 & 0,242 & 0,929 & 0,971 \\
\hline \multirow{2}{*}{ Padrão 2} & Prod. Merc & 0,988 & 0,342 & 0,637 & 0,236 & 0,014 & 0,000 & 0,937 & 0,819 \\
\hline & Prod. Empr & 0,028 & 0,837 & 0,004 & 0,459 & 0,462 & 0,541 & 0,069 & 0,057 \\
\hline \multirow{2}{*}{ Padrão 3} & Prod. Merc & 0,894 & 0,751 & 0,845 & 0,420 & 0,896 & 0,650 & 0,581 & 0,341 \\
\hline & Prod. Empr & 0,460 & 0,971 & 0,265 & 0,589 & 0,977 & 0,003 & 0,119 & 0,001 \\
\hline \multirow{2}{*}{ Padrão 4} & Prod. Merc & 0,001 & 0,124 & 0,052 & 0,000 & 0,503 & 0,275 & 0,065 & 0,001 \\
\hline & Prod. Empr & 0,000 & 0,030 & 0,001 & 0,003 & 0,242 & 0,812 & 0,216 & 0,617 \\
\hline \multirow{2}{*}{ Caso Geral } & Prod. Merc & 0,647 & 0,247 & 0,017 & 0,036 & 0,014 & 0,201 & 0,137 & 0,003 \\
\hline & Prod. Empr & 0,003 & 0,516 & 0,000 & 0,035 & 0,000 & 0,358 & 0,001 & 0,000 \\
\hline
\end{tabular}

Fonte: Elaboração própria. 


\section{Anexo Estatístico II}

Tabela A6 R-quadrado das regressões simples para o caso geral

\begin{tabular}{|c|c|c|c|c|c|c|c|c|c|c|c|c|}
\hline & \multicolumn{12}{|c|}{ R-QUADRADO CASO GERAL } \\
\hline & 홀 흘 & 현 잏 & 올 흘 & ن் & 옹 홀 & 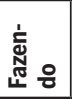 & ๖ & 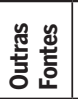 & d & 㝘 & 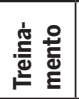 & 完 \\
\hline \multicolumn{13}{|l|}{ Prod. Emp. } \\
\hline Prod. Merc & - & & & & & & & & & & & \\
\hline Proc. Emp. & - & - & & & & & & & & & & \\
\hline Proc. Merc & - & - & - & & & & & & & & & \\
\hline P\&D Interno & 0,00 & 0,31 & 0,40 & 0,24 & & & & & & & & \\
\hline Fazendo & 0,00 & 0,11 & 0,09 & 0,05 & 0,20 & & & & & & & \\
\hline C\&T Avançada & 0,00 & 0,07 & 0,10 & 0,07 & 0,23 & 0,29 & & & & & & \\
\hline Outras Fontes & 0,00 & 0,00 & 0,00 & 0,00 & 0,04 & 0,13 & 0,46 & & & & & \\
\hline Fornecedores & 0,05 & 0,23 & 0,32 & 0,04 & 0,05 & 0,00 & 0,00 & 0,06 & & & & \\
\hline Clientes & 0,04 & 0,20 & 0,29 & 0,04 & 0,34 & 0,19 & 0,23 & 0,10 & 0,00 & & & \\
\hline Treinamento & 0,00 & 0,00 & 0,00 & 0,00 & 0,06 & 0,18 & 0,31 & 0,28 & 0,19 & 0,12 & & \\
\hline Imitação & 0,00 & 0,00 & 0,01 & 0,01 & 0,06 & 0,05 & 0,12 & 0,09 & 0,06 & 0,18 & 0,21 & \\
\hline
\end{tabular}

Fonte: Elaboração própria.

Tabela A7 R-quadrado das regressões simples para o Padrão 1

\begin{tabular}{|c|c|c|c|c|c|c|c|c|c|c|c|c|}
\hline & \multicolumn{12}{|c|}{ R-QUADRADO PADRÃO 1} \\
\hline & 홀 & ᄒ்่ & نे & ن் & \& & $\begin{array}{l}\text { 它 } \\
\text { ్ㅗㅇ 응 }\end{array}$ & 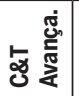 & 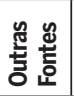 & 형 & 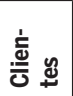 & 密 윻 & 沍 \\
\hline \multicolumn{13}{|l|}{ Prod. Emp. } \\
\hline Prod. Merc & - & & & & & & & & & & & \\
\hline Proc. Emp. & - & - & & & & & & & & & & \\
\hline Proc. Merc & - & - & - & & & & & & & & & \\
\hline P\&D Interno & 0,07 & 0,05 & 0,25 & 0,10 & & & & & & & & \\
\hline Fazendo & 0,00 & 0,07 & 0,05 & 0,03 & 0,13 & & & & & & & \\
\hline C\&T Avançada & 0,07 & 0,01 & 0,05 & 0,03 & 0,01 & 0,16 & & & & & & \\
\hline Outras Fontes & 0,08 & 0,03 & 0,16 & 0,02 & 0,09 & 0,06 & 0,63 & & & & & \\
\hline Fornecedores & 0,14 & 0,19 & 0,36 & 0,00 & 0,02 & 0,09 & 0,25 & 0,27 & & & & \\
\hline Clientes & 0,05 & 0,16 & 0,23 & 0,01 & 0,15 & 0,00 & 0,00 & 0,00 & 0,02 & & & \\
\hline Treinamento & 0,05 & 0,02 & 0,07 & 0,00 & 0,00 & 0,01 & 0,23 & 0,11 & 0,32 & 0,00 & & \\
\hline Imitação & 0,01 & 0,01 & 0,03 & 0,00 & 0,00 & 0,00 & 0,14 & 0,09 & 0,09 & 0,05 & 0,26 & \\
\hline
\end{tabular}

Fonte: Elaboração própria. 
Tabela A8 R-quadrado das regressões simples para o Padrão 2

\begin{tabular}{|c|c|c|c|c|c|c|c|c|c|c|c|c|}
\hline & \multicolumn{12}{|c|}{ R-QUADRADO PADRÃO 2} \\
\hline & 홀 竞 & 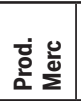 & 它家 & نั & ఖे & 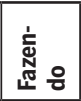 & 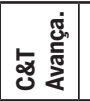 & 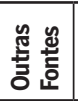 & 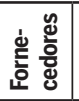 & 㝘 & 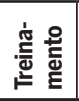 & 䆠突 \\
\hline \multicolumn{13}{|l|}{ Prod. Emp. } \\
\hline Prod. Merc & - & & & & & & & & & & & \\
\hline Proc. Emp. & - & 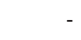 & & & & & & & & & & \\
\hline Proc. Merc & - & - & - & & & & & & & & & \\
\hline P\&D Interno & 0,00 & 0,23 & 0,25 & 0,21 & & & & & & & & \\
\hline Fazendo & 0,03 & 0,04 & 0,01 & 0,08 & 0,01 & & & & & & & \\
\hline C\&T Avançada & 0,00 & 0,03 & 0,05 & 0,06 & 0,22 & 0,04 & & & & & & \\
\hline Outras Fontes & 0,00 & 0,01 & 0,00 & 0,00 & 0,07 & 0,02 & 0,30 & & & & & \\
\hline Fornecedores & 0,12 & 0,02 & 0,15 & 0,00 & 0,02 & 0,00 & 0,02 & 0,01 & & & & \\
\hline Clientes & 0,05 & 0,20 & 0,28 & 0,04 & 0,21 & 0,04 & 0,11 & 0,11 & 0,03 & & & \\
\hline Treinamento & 0,01 & 0,02 & 0,00 & 0,00 & 0,05 & 0,07 & 0,09 & 0,12 & 0,07 & 0,05 & & \\
\hline Imitação & 0,01 & 0,00 & 0,00 & 0,00 & 0,03 & 0,00 & 0,02 & 0,00 & 0,02 & 0,07 & 0,09 & \\
\hline
\end{tabular}

Fonte: Elaboração própria.

Tabela A9 R-quadrado das regressões simples para o Padrão 3

\begin{tabular}{|c|c|c|c|c|c|c|c|c|c|c|c|c|}
\hline & \multicolumn{12}{|c|}{ R-QUADRADO PADRÃO 3} \\
\hline & 힐 흘 & छ் & 它 & 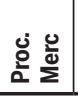 & ळ & 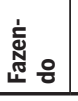 & ๒ & 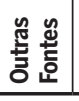 & 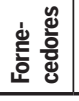 & 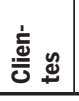 & 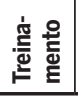 & 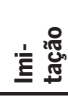 \\
\hline \multicolumn{13}{|l|}{ Prod. Emp. } \\
\hline Prod. Merc & - & & & & & & & & & & & \\
\hline Proc. Emp. & - & & & & & & & & & & & \\
\hline Proc. Merc & - & - & - & & & & & & & & & \\
\hline P\&D Interno & 0,18 & 0,27 & 0,02 & 0,21 & & & & & & & & \\
\hline Fazendo & 0,02 & 0,05 & 0,02 & 0,08 & 0,34 & & & & & & & \\
\hline C\&T Avançada & 0,02 & 0,00 & 0,07 & 0,03 & 0,14 & 0,46 & & & & & & \\
\hline Outras Fontes & 0,05 & 0,01 & 0,01 & 0,04 & 0,00 & 0,22 & 0,36 & & & & & \\
\hline Fornecedores & 0,09 & 0,08 & 0,15 & 0,13 & 0,10 & 0,15 & 0,04 & 0,03 & & & & \\
\hline Clientes & 0,01 & 0,11 & 0,09 & 0,16 & 0,34 & 0,34 & 0,12 & 0,00 & 0,12 & & & \\
\hline Treinamento & 0,01 & 0,00 & 0,00 & 0,02 & 0,14 & 0,32 & 0,26 & 0,25 & 0,40 & 0,20 & & \\
\hline Imitação & 0,00 & 0,02 & 0,03 & 0,02 & 0,03 & 0,09 & 0,01 & 0,06 & 0,08 & 0,20 & 0,11 & \\
\hline
\end{tabular}

Fonte: Elaboração própria. 
Tabela A10 R-quadrado das regressões simples para o Padrão 4

\begin{tabular}{|c|c|c|c|c|c|c|c|c|c|c|c|c|}
\hline & \multicolumn{12}{|c|}{ R-QUADRADO PADRÃO 4} \\
\hline & ㅎํㄹ 흘 & 홀 농 & ن호 흘 & 어 인 & 옳 & $\begin{array}{l}\text { 亡ㄹㅀ } \\
\text { 폰 응 }\end{array}$ & ヶ & 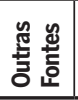 & 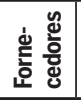 & 它 & 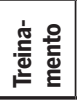 & 트 \\
\hline \multicolumn{13}{|l|}{ Prod. Emp. } \\
\hline Prod. Merc & - & & & & & & & & & & & \\
\hline Proc. Emp. & - & - & & & & & & & & & & \\
\hline Proc. Merc & - & - & - & & & & & & & & & \\
\hline P\&D Interno & 0,00 & 0,02 & 0,36 & 0,32 & & & & & & & & \\
\hline Fazendo & 0,00 & 0,00 & 0,01 & 0,01 & 0,04 & & & & & & & \\
\hline C\&T Avançada & 0,00 & 0,05 & 0,11 & 0,10 & 0,11 & 0,10 & & & & & & \\
\hline Outras Fontes & 0,01 & 0,00 & 0,00 & 0,01 & 0,02 & 0,00 & 0,28 & & & & & \\
\hline Fornecedores & 0,07 & 0,40 & 0,49 & 0,22 & 0,16 & 0,00 & 0,02 & 0,01 & & & & \\
\hline Clientes & 0,05 & 0,02 & 0,00 & 0,02 & 0,00 & 0,01 & 0,08 & 0,03 & 0,10 & & & \\
\hline Treinamento & 0,00 & 0,02 & 0,03 & 0,02 & 0,01 & 0,08 & 0,20 & 0,16 & 0,06 & 0,04 & & \\
\hline Imitação & 0,06 & 0,12 & 0,00 & 0,00 & 0,02 & 0,00 & 0,02 & 0,02 & 0,10 & 0,14 & 0,04 & \\
\hline
\end{tabular}

Fonte: Elaboração própria. 